\title{
Numerical Eddy-Resolving Modeling of the Ocean: Mesoscale and Sub-Mesoscale Examples
}

\author{
E. V. Stanev ${ }^{1,}$, M. Ricker ${ }^{1,2}$, S. Grayek ${ }^{1}$, B. Jacob ${ }^{1}$, V. Haid ${ }^{1,3}$, \\ J. Staneva ${ }^{1}$ \\ ${ }^{1}$ Helmholtz-Zentrum Geesthacht, Geesthacht, Germany \\ ${ }^{2}$ Institute for Chemistry and Biology of the Marine Environment, University of Oldenburg, \\ Oldenburg, Germany \\ ${ }^{3}$ Alfred Wegener Institute Helmholtz Centre for Polar and Marine Research, Bremerhaven, Germany \\ 凶emil.stanev@hzg.de
}

Purpose. The study addresses rotational motion of geophysical fluids in the horizontal and vertical planes. It is aimed mainly at tracing the development of high-resolution numerical modeling of the ocean, as well as at demonstrating new physical processes due to more correct consideration both of the tides in the eddy-resolving numerical models and sub-mesoscale dynamics in the models of the sea straits.

Methods and Results. The ocean eddies and their interaction with tides are studied using numerical simulations by four NEMO models for the European North-West shelf with the resolutions ranging from 7 to $1.5 \mathrm{~km}$. The vertical characteristics of motion in the Bosporus Strait were studied using numerical simulations with SCHISM, the unstructured grid model with the ultra-fine model resolution (less than $100 \mathrm{~m}$ ). The barotropic tidal forcing resulted in substantial flattening of the slopes of the spectral curves. The most important difference between the spectral features of four models occurs in the motion rotational component. In the model with the $1.5 \mathrm{~km}$ resolution, the magnitude of the vorticity power spectral density at the scales $\sim 70 \mathrm{~km}$ is by an order of magnitude higher than in the other three models. Although most of the tidal flattening is associated with the internal tides, beyond a certain horizontal resolution, the eddy dynamics become affected by the barotropic tides. The shelf of the Biscay Bay and the shallows around the Faroe Islands are the most sensitive areas to adding of the barotropic tides to the model forcing. Due to the grid ultra-fine resolution, new elements of physical motion emerged in the Bosporus region. The lateral circulation is dominated by the systems of multiple circulation cells with the scales $\sim 1 \mathrm{~km}$. In some areas, the lateral flow magnitude exceeds $0.5 \mathrm{~m} / \mathrm{s}$, which is comparable with the magnitude of the axial flow. This reveals importance of the helical elements of the strait circulation for overturning of water masses in the Bosporus.

Conclusions. Without proper resolution, the models of tidal oceanic dynamics simulate the ocean general circulation, but do not describe correctly the energy cascades at the eddy scales including interaction between the tides and the mesoscale eddies. Absence of this sub-mesoscale dynamics in the models can largely affect their capability to simulate the two-layer inter-basin exchange.

Keywords: ocean eddies, numerical ocean models, horizontal resolution, inter-basin exchange

Acknowledgements: the study was carried out at support of the Initiative and Networking Fund of the Helmholtz Association within the framework of the project "Advanced Earth System Modelling Capacity".

For citation: Stanev, E.V., Ricker, M., Grayek, S., Jacob, B., Haid, V. and Staneva, J., 2020. Numerical Eddy-Resolving Modeling of the Ocean: Mesoscale and Sub-Mesoscale Examples. Physical Oceanography, [e-journal] 27(6), pp. 631-658. doi:10.22449/1573-160X-2020-6-631-658

DOI: 10.22449/1573-160X-2020-6-631-658

(c) E. V. Stanev, M. Ricker, S. Grayek, B. Jacob, V. Haid, J. Staneva, 2020

(C) Physical Oceanography, 2020

\section{Introduction}

The rotational motions of fluids has inspired leaders from different fields. In the Codex Leicester, Leonardo da Vinci (1510; cited from [1]) depicted 
the infinite variability of vortices. About 350 years later, Helmholtz [2] developed the basic theorems of the vortex theory. In geophysical fluid dynamics (fluid dynamics on Earth and other rotating planets), there is a fundamental number called the Rossby radius of deformation $\mathrm{R}_{\mathrm{d}}=\left(g^{\prime} H\right)^{1 / 2} / f$, which measures the length scale at which rotational effects become as important as the ones caused by gravity. In this formula, $H$ is the vertical scale of the flow, $f$ is the Coriolis parameter, and $g^{\prime}$ is the reduced gravity, which is the gravitational acceleration multiplied by the change of the potential density over the vertical scale $H$. To say it in other words, $R_{d}$ is the "natural" scale of eddies and fronts.

The generation of eddies in the ocean is practically identical to the process known as baroclinic instability. It is also responsible for the generation of cyclones and anticyclones in the atmosphere. Because the reduced gravity is smaller in the ocean than in the atmosphere, eddies there are also smaller (typical horizontal scales of less than $100 \mathrm{~km}$ ), and their timescales (on the order of a month) are longer than those of the synoptic motion in the atmosphere. The small size of the ocean eddies is perhaps one of the reasons why they were discovered later than their atmospheric counterparts. Ocean eddies were discovered first in 1970 during the Polygon-70 experiment [3, 4]. The observational array included 17 buoys placed on a cross of 120 miles $(193 \mathrm{~km})$ in zonal and meridional direction with a center at $16.5^{\circ}$ north and $33.5^{\circ}$ west. This experiment continued for more than seven months and discovered an anticyclonic eddy with a diameter of $\sim 200 \mathrm{~km}$. We remind that this eddy was large because of the small values of the Coriolis parameter between the tropics and the equator.

Polygon-70 was followed from March through mid-July 1973 by the MidOcean Dynamics Experiment (MODE-1), which was designed to investigate mesoscale eddies in an area southwest of Bermuda [5]. In 1977-1978, US and Soviet Union joined forces in the experiment called POLYMODE (the name was a combination of Polygon and MODE) with the aim of advancing the science on eddy motion in the ocean [6]. The first author of this study, who participated in POLYMODE in the 27th cruise of R/V Kurchatov, took at the time of MODE-1 his first steps in the field of numerical modelling of the ocean. Limited computational resources and experience with numerical ocean modelling at that time were obstacles to the simulation of the dynamics at eddy scales. Only in 1992 Semtner and Cherwin described a concerted effort to simulate the global ocean circulation with resolved eddies [7]. However, their model with a resolution of $0.5^{\circ}$ (which is about $50 \mathrm{~km}$ ) could hardly resolve mesoscale eddies, many of which have the size of their grid. Ten years after this pioneering work, global models reached a resolution of $1 / 10^{\circ}[8,9]$ demonstrating a major step forward in high resolution ocean modeling, with applications to prediction and climate. The resolution in current global models $\left(1 / 12^{\circ}\right.$ in [10] and $1 / 16^{\circ}$ in [11]) is even superior to that of the first limited area eddy resolving models $(\sim 20 \mathrm{~km}$ in [12]) from the time of POLYMODE.

Now it's time also to address processes at sub-mesoscales. It is generally accepted that submesoscale processes in the ocean [13] are characterized by scales of $1-10 \mathrm{~km}$, which is smaller than the Rossby radius of deformation. Their temporal scales are shorter than a few hours and their relative vorticity is greater than $f$ (for the mesoscale motion the relative vorticity is only comparable to $f$ ). 
With the available observational techniques, and given the small size and strong temporal variability, it is very difficult to observe sub-mesoscale eddies in the real ocean. Their most visible appearances are in the color pictures of chlorophyl at the ocean surface. Although the satellite color data provide good-quality snapshots, the temporal evolution is difficult to record. While numerical modelling is also a challenge, with the present day developments of computational techniques and unstructured-grid modelling, the perspectives look not bad.

Mesoscale eddies are known to interact with internal gravity waves and convection. They affect the strength of large-scale currents and heat transport across the ocean fronts. As the resolution of numerical models gradually improves, there are scales, beyond which one passes specific thresholds and new phenomena occur, which are not present at lower resolution. The interaction between eddy processes and many other processes could also change dramatically in fineresolution models. The fine resolution of bathymetry can also substantially change the regional dynamics of models in particular in ocean straits, which are of crucial importance for the exchange of water masses between different basins. This exchange can take different forms depending on how adequately the dominant scales are resolved [14].

There are a plethora of ocean cases, which nicely illustrate the coupling between different ocean processes and eddies. In the present work, we will present two examples. One of them illustrates the interplay between eddies and barotropic tides. This issue has recently been addressed by [15] for the area of the Biscay Bay, where authors used the Nucleus for European Modelling of the Ocean NEMO v3.6 [16] and analyzed the effect of turning the tidal forcing on and off. The robustness of results depending on the model resolution was beyond the scope of the work [15] and will be addressed in the present study. We consider it a very important issue because eddy processes show strong model dependence.

The second element of ocean dynamics addressed in the present study is the secondary (lateral) circulation in ocean channels. Secondary circulation describes the flows perpendicular to the channel's axis [17]. The authors of [14] studied the straits connecting the Baltic Sea to the North Sea (Fig. 1, a), and compared $A D C P$ observations and numerical simulations performed with the Semiimplicit Cross-scale Hydroscience Integrated System Model SCHISM [18]. They demonstrated that new elements of physical motion in the straits appear as a result of using an ultra-fine model resolution (grid size less than $\sim 100 \mathrm{~m}$ ). Here, we will present a similar situation for the strait system connecting the Black Sea with the Mediterranean.

There is a reasonable question of why one would address eddies and channel flows in the same paper. The connecting element of the two types of motion is the rotation. In 2020, exactly 500 years passed since the death of Leonardo da Vinci. He not only put the rotational motion in the focus of his interest, but also studied velocity profiles in channels, along with the role of friction [19]. Now, we begin to understand that the exchange flows in ocean straits are rotational in crosschannel direction. This paper is structured as follows: in section 2, we first present the models and the geographical settings, for which we apply them. We present the results on the eddy dynamics in the Bay of Biscay in section 3 and section 4 presents an analysis of the secondary circulation in the strait of Bosporus, followed by brief conclusions. 
a)

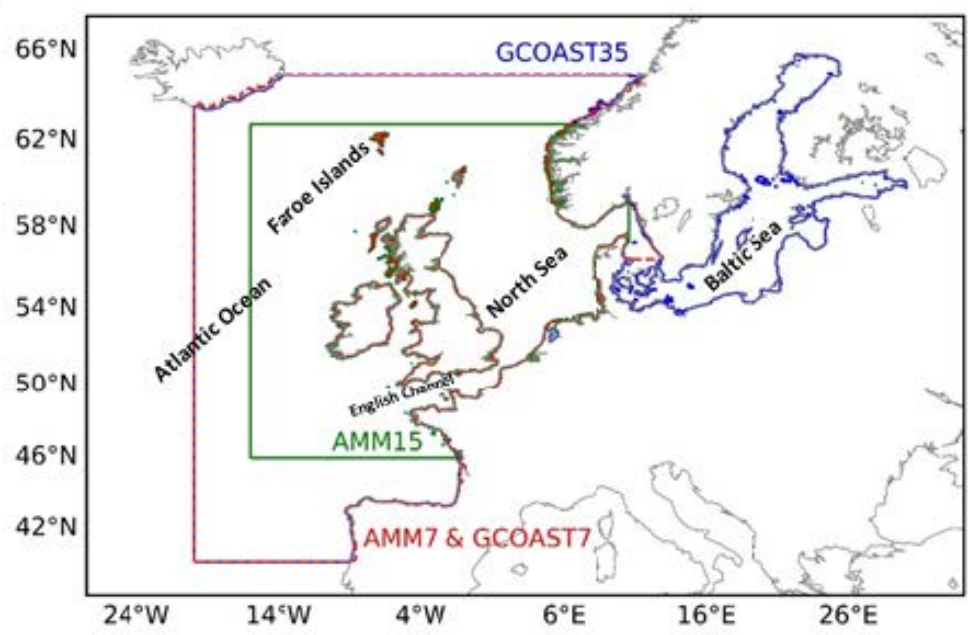

b)

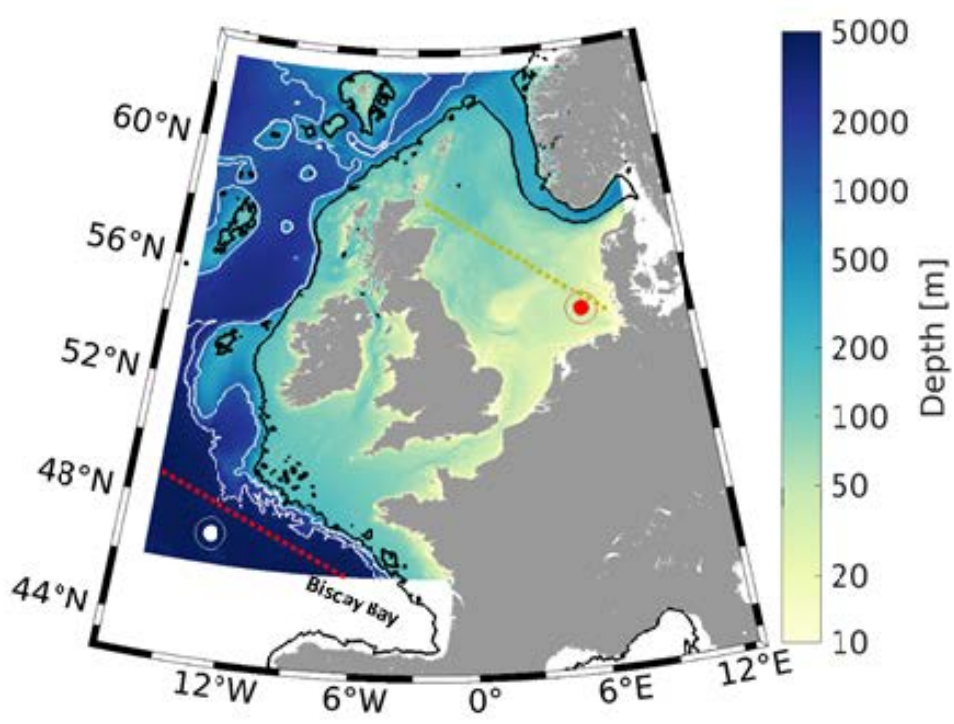

Fig. 1. The Baltic Sea, the North Sea and part of the East Atlantic - $a$. The areas of GCOAST7, AMM7 (red), GCOAST35 (blue), and AMM15 (green) are also shown (see the text for description of the individual models). Fragment $(b)$ shows the part of the area in (a) where most of analyses are performed, e. g., the section lines and two specific locations. The colored background denotes bathymetry (the 200 (thick black line), 1000, and $3000 \mathrm{~m}$ isobaths are also shown) 


\section{The regional environmental settings and models used}

\section{1. The European Northwest Shelf and the adjacent deep ocean}

\subsection{Dynamics}

The studied area is a typical representative of tidally-driven ocean dynamics. However, many numerical ocean circulation models do not simulate mesoscale eddies and tides. Either the models are barotropic, or the resolution is too coarse, or tides are not included. In such a case, the uncertainties resulting from the underrepresentation of the respective interactions between barotropic tides and mesoscale motion remain unknown. When the scales of tidally-driven motion (e. g., internal tide) and geostrophic eddies become comparable, the interactions between these two elements of ocean dynamics start to dominate ocean motion [20, 21]. This interaction is regionally dependent because the bahymetry has a large impact on the transfer of energy from barotropic to baroclinic tides [22-26].

The study [15] can be considered an application of the theories of tide-eddy interactions [27-29] for the transition areas between shelves, continental slopes, and deep oceans. For their analysis, the authors of [15] have chosen the European Northwest Shelf (ENWS, Fig. 1, b) because it is known from earlier works that there, the shelf-deep water interactions depend strongly on tides [30-32]. The tidal forcing in these areas intensifies the transient processes and results in a substantial transformation of the wave number spectra. The authors of [15] attributed this transformation to the contribution of the processes in the high-frequency range. The simulated slopes of spectral curves differed from those known from the theory of quasigeostrophic (QG) turbulence. They featured distinct differences along and across the continental slope suggesting that the mesoscale turbulence was not isotropic. These findings motivated us to deepen the analysis on how the mesoscale eddies and their energy cascade vary in different models.

\section{1. 2. NEMO setups}

The interaction of barotropic tides and mesoscale eddies in models depends on how well eddies are resolved. At least two grid points per radius of deformation are needed to resolve an eddy [33]. In the study [15], with a resolution of $7 \mathrm{~km}$, eddies with diameters larger than 30-40 km and internal tides with comparable length scales were resolved. In [34-36] different aspects of the impact of model resolution on the performance of models set up for the region of the ENWS, including operational models, were studied. The authors of [37, 38] developed a very fine resolution model $(1.5 \mathrm{~km})$ for the ENWS area, which is known as the AMM15 (Atlantic Margin Model, 15 stands for $1.5 \mathrm{~km}$ resolution). It is the next-generation ocean model for the ENWS for operational forecasting replacing AMM7 (7 stands for $7 \mathrm{~km}$ resolution [39]).

In the present study, we analyse data from numerical simulations using the model described in [15], AMM7 and AMM15. These models are already documented in the works cited above. Additional simulations have been performed using the Helmholtz-Zentrum Geesthacht (HZG) version of the Nucleus for European Modelling of the Ocean (NEMO v3.6; [16]) with $3.5 \mathrm{~km}$ horizontal resolution. The respective model setup is part of the Geesthacht COAstal model SysTem (GCOAST), which is a coupled modeling framework that includes atmospheric, oceanic, wind wave, biogeochemical and hydrological parts [40]. 
Here, we use only the ocean circulation part. The model area covers the Baltic Sea, the Danish Straits, the North Sea and part of the Northeast Atlantic (Fig. 1, a). Our analysis focusses on the region shown in Fig. 1, $b$. The vertical discretization uses 50 hybrid s-z* levels with partial cells. The model forcing for the momentum and heat fluxes is computed using bulk aerodynamic formulas and hourly data from atmospheric reanalyses of the European Centre for Medium Range Weather Forecasts (ERA5 ECMWF with a horizontal resolution of $0.25^{\circ}$ ). The tidal potential is also included in the model forcings [41]. The daily climatology for the river run-off is based on river discharge datasets from the German Federal Maritime and Hydrographic Agency (Bundesamt für Seeschifffahrt und Hydrographie, BSH), the Swedish Meteorological and Hydrological Institute (SMHI) and the United Kingdom Meteorological Office (Met Office). The boundary conditions at the open boundaries use input from AMM7 [39] distributed by the Copernicus Marine Environment and Monitoring Service. The output is stored hourly for 2016 and 2017. Data assimilation is not used. In the following, this model will be named GCOAST35. The model used in [15], which differs from the GCOAST35 mainly by the two times coarser resolution, will be named GCOAST7 (7 and 35 correspond to 7 and $3.5 \mathrm{~km}$ resolution). GCOAST7 has been presented in detail in [15].

Two experiments, similar to those described in [15] have been performed with GCOAST35. The first, which used the full forcing described above, is called control run GCOAST35-CRE (CRE stands for control run experiment). In the second experiment (GCOAST35-NTE) tides were turned off (NTE stands for nontidal experiment). The corresponding CRE and NTE of GCOAST7 were analysed in [15] and were named CRE and NTE there. A small part of these earlier results will also be used in the present work.

\section{2. The narrow ocean straits}

\section{2. 1. The cascade from the Azov Sea to Mediterranean}

Narrow and shallow straits, like the Bosporus Strait $(\sim 1 \mathrm{~km}$ wide and $\sim 30 \mathrm{~m}$ shallow at places), provide connections between large water bodies with different salinities. The dynamics in such straits is largely unknown, not least because the incapability of existing structured grid models to accurately resolve the dominant processes. As demonstrated in [42], unstructured grid modelling contributes largely to our understanding of the water exchange in the cascade consisting of the Azov Sea - Black Sea - Marmara Sea - Aegean Sea, which is one of the largest estuarine systems worldwide. In this cascade, the long-term mean transport is driven by the water balance and modulated by winds and atmospheric pressure. In vertical direction, the structure of currents is similar to that of the tidal estuaries. The upper-layer flow is from the less to the more saline basins, the bottom-layer flow is in the opposite direction. Salinity in the Black Sea ranges from 17-18 at the surface (areas around the river mouths are excluded) to $\sim 22.3$ in the deepest bottom layers. In the Marmara Sea, salinity ranges from $\sim 22$ at the surface to more than 38 at $\sim 50 \mathrm{~m}$ and increases very little down to the bottom.

The evaporation $\left(\sim 350 \mathrm{~km}^{3}\right.$ year-1) and precipitation $\left(\sim 300 \mathrm{~km}^{3}\right.$ year-1) over the Black Sea tend to cancel each other out, therefore the net outflow of $\sim 300 \mathrm{~km}^{3}$ per year through the Bosporus is only $\sim 50 \mathrm{~km}^{3}$ year-1 smaller than the river runoff 
plus the inflow from the Azov Sea [43]. Here and in the following, we define outflow (inflow) in the Bosporus as the water leaving (entering) the Black Sea. The ratio between the two flows is approximately $2: 1$, which sets the approximate ratio between the salinities in the Black Sea and Mediterranean as $1: 2$. These ratios follow from the conservation of mass and salt. The model presented in [42] shows a good skill in simulating the strait dynamics and gravity currents originating from the straits. The timing and magnitude of exchange flows are realistically simulated, as well as the dependence of the two-layer flow upon the net transport. The overall conclusion from this research was that modeling the individual basins in separation or connecting them with poorly resolved straits could result in large inaccuracies because the missing fundamental processes dominating the inter-basin exchange.

In more recent studies on the two-layer exchange in the interconnection zone between the Baltic Sea and the North Sea (a system similar to the cascade described above), the authors of $[14,44]$ studied the secondary circulation in the Danish Straits based on observations and numerical modelling using an unstructured-grid hydrodynamic model. They demonstrated that with a resolution of $\sim 100 \mathrm{~m}$ in the straits, new transport and mixing pathways appear, which are fundamental to the strait dynamics. The lateral circulation is structured in a number of helical cells with horizontal scales of $\sim 1 \mathrm{~km}$. Helixes disappear in the simulations performed with a coarser grid of $\sim 500 \mathrm{~m}$.

\section{2. 2. SCHISM set up}

In the present study, we analyze the results from the model for the chain of cascading basins from the Azov to the Aegean Sea (Fig. 2) described in [42]. This model uses the numerical code of the unstructured grid model SCHISM [18]. This model originates from the semi-implicit Eulerian - Lagrangian finite-element (SELFE) model [45]. A number of improvements, which were implemented in SCHISM are described in [18]. SCHISM solves the Reynolds-averaged Navier Stokes equations and equations for the transport of heat and salt. The model grid is a hybrid finite-element and finite volume grid. All terms that place stringent stability constraints (e.g., CFL) are treated implicitly and an Eulerian - Lagrangian method for the momentum advection is used. Further technical details are given in the above-cited works.

The cascade-model setup uses mixed triangular-quadrangular elements in the horizontal direction and the flexible vertical grid system LSC2 [46]. As demonstrated in [42], the model resolves the baroclinic instability and a number of cross-scale processes ranging from straits-scales to basin-scales in a seamless fashion. The computational grid has $\sim 104 \mathrm{~K}$ nodes and $\sim 178 \mathrm{~K}$ triangles/quadrangles. The minimum side length of the grid is $\sim 80 \mathrm{~m}$ in the Bosporus and Dardanelles Straits. In the remaining area, an essentially uniform resolution of $3 \mathrm{~km}$ is used. This is enough to resolve mesoscale eddies. The vertical grid consists of up to 53 levels in the deep ocean, with an average number of 31.65 levels in the whole model domain. The bathymetry, which is described in [42], was not smoothed. 

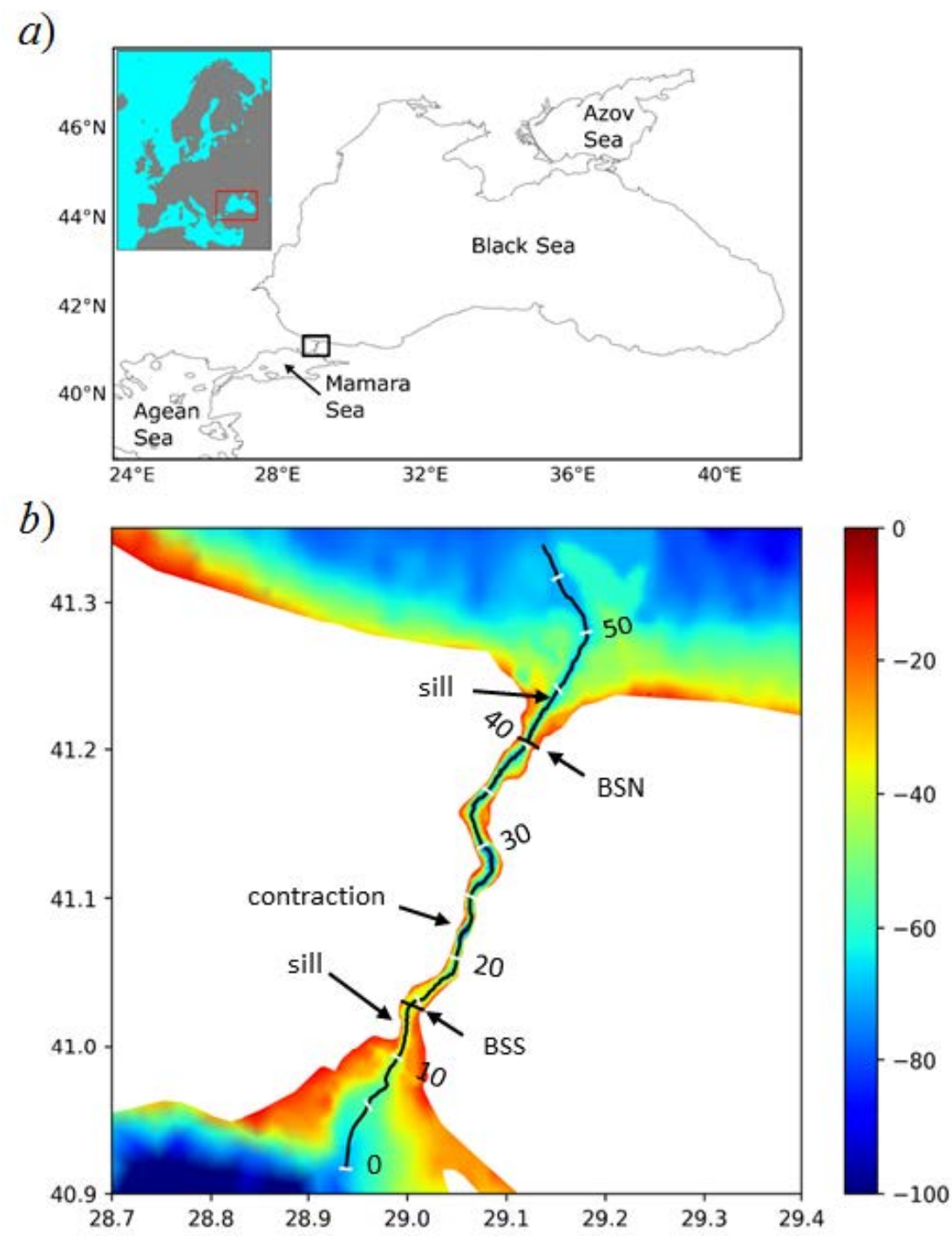

F i g. 2. The cascade of interconnected basins: the Azov Sea, the Black Sea, the Marmara Sea and the Aegean Sea $-a$. Position of the Black Sea is shown as an inset in the upper-left corner. The box shows the region represented in $b$; also shown are the Bosporus Strait bathymetry, the section line (numbers are kilometers from the beginning) and specific locations for which the simulation analyses are represented in the text. Two sections are given: the southern and northern Bosporus Strait

\section{Eddy dynamics on the shelf, continental slope and deep ocean}

\subsection{Tides simulated in 7 and $3.5 \mathrm{~km}$ resolution models}

With the tidal forcing, which is prescribed in GCOAST35 and GCOAST7 in the same way, the variability due to the major tidal constituents is almost identical (compare the amplitude of $M 2$ tide in Fig. 3 with Fig. 3, $a$ of [15, p. 717]). The amplitude was computed using the tidal harmonic analysis method UTide [47]. 
The largest deviations between the two models occur in the English Channel, in front of the mouth of the Elbe River, and in the Irish Sea. However, these deviations are small compared to the respective amplitudes, which allows to conclude that the barotropic tides in the two models are almost identical. Comparisons with independent data presented in Fig. 3, b and Fig. 3, $c$ of [15], show that the simulations are realistic with respect to the tides. Analysis of the other important tidal constituents simulated in the two models (not shown here) also reveals a very good agreement between GCOAST35 and GCOAST7.

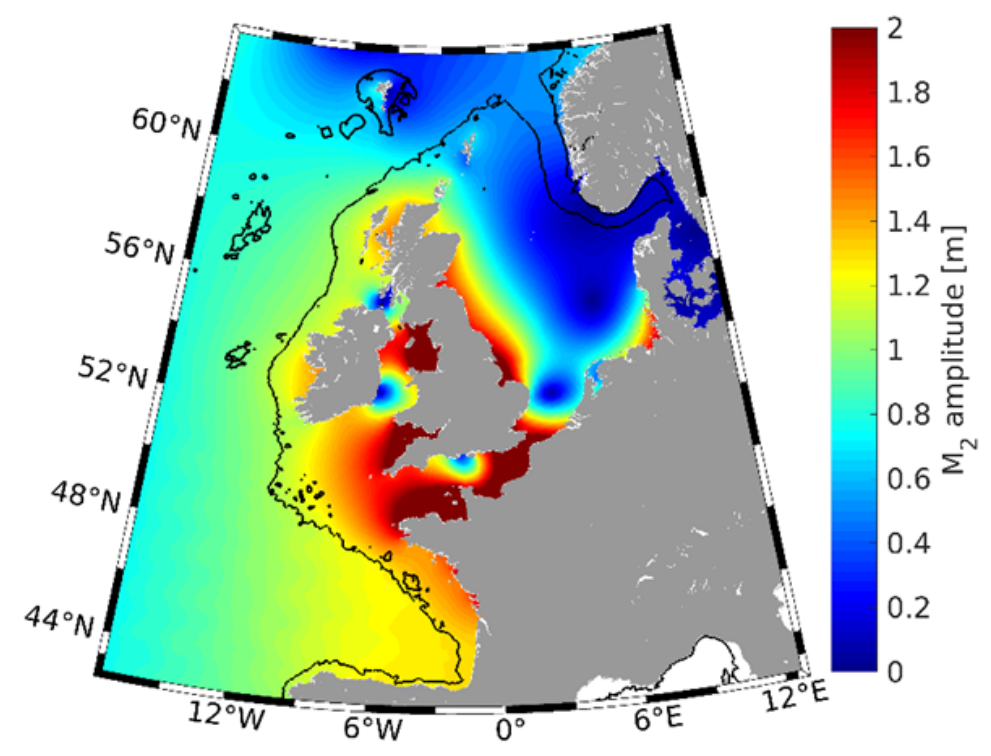

F i g. 3. Amplitude of the $M 2$ tide in the GCOAST35 model for the period from January 1 to June 30 , 2015 computed from the simulated sea level using UTide

The velocity spectra in the deep ocean $(100 \mathrm{~m})$ and on the shelf (sea surface) demonstrate that the $M 2$ tide is the most important high-frequency signal (Fig. 4). Its amplitude is almost the same in GCOAST35 and GCOAST7. A secondary peak occurs at inertial frequency. The analysis of GCOAST35 data shows slightly lower inertial amplitudes in the deep ocean than the GCOAST7 one, however the differences are dependent on locations. In the considered locations (see Fig. 1), the amplitudes of the $M 2$ tide estimated from zonal velocities are an order of magnitude higher on the shelf than in the deep ocean (compare Fig. 4, $a, c$ with Fig. $4, b, d$, respectively). Here, we remind that the amplitude of M2 tide in the deep ocean remains almost constant in the upper $100 \mathrm{~m}$. Furthermore, on the shelf, the inertial motion is suppressed by the strong friction in both models (the inertial peak does not appear in the right-hand side panels in Fig. 4). This numerical result is consistent with the analysis of observations presented in [48]. Comparisons with the data from AMM7 and AMM15 (not shown here) demonstrate that the frequency spectra are almost the same in the four models. The largest differences occur in the deep ocean where the amplitudes are 
overestimated in AMM7 and underestimated in GCOAST7 compared to the finer resolution model.

a)

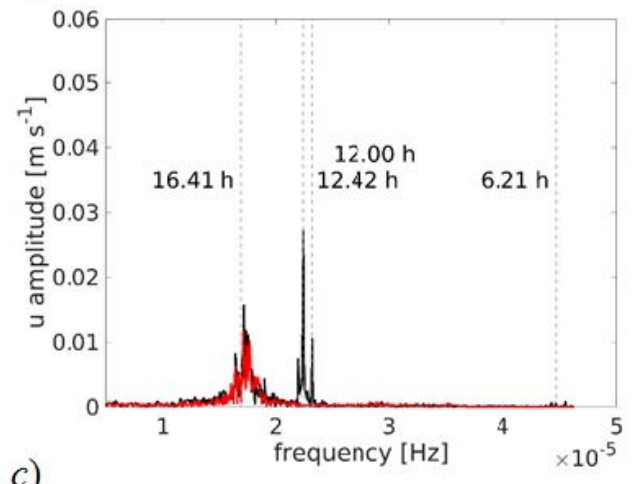

c)

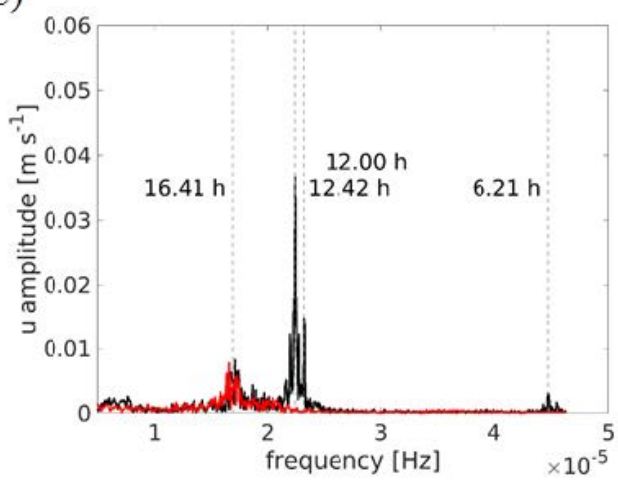

b)

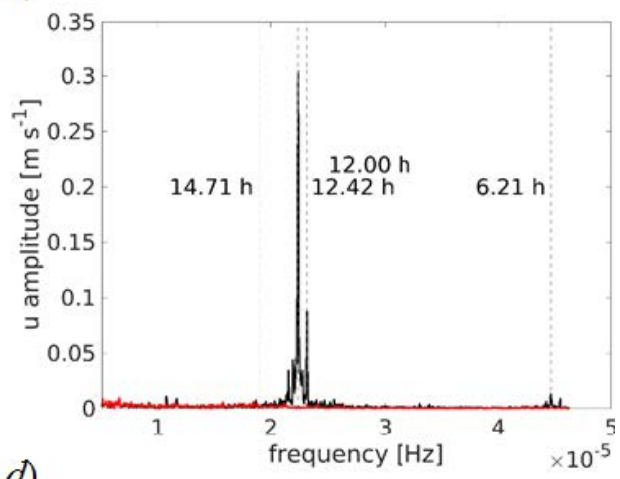

d)

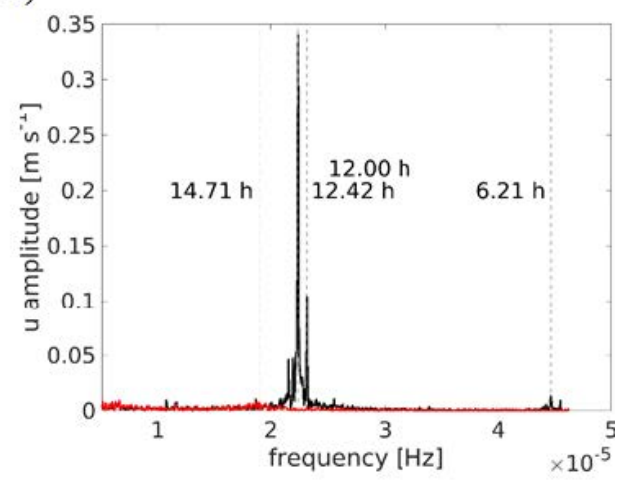

F i g. 4. Velocity frequency spectrum $u$ at the $100 \mathrm{~m}$ in the deep ocean (left panels) and at the sea surface in the German Bight (right panels). See the station positions $\left(47.0^{\circ} \mathrm{N}, 15.78^{\circ} \mathrm{W}\right.$ and $54.67^{\circ} \mathrm{N}$, $6.56^{\circ} \mathrm{E}$ ) in Fig. 1. Analysis is for the period from January 1, 2015 to June 30, 2015. Plots on the top are from GCOAST7, the ones on the bottom - from GCOAST35. Black line - CRE, and red line NTE. Dashed vertical lines and the corresponding numbers indicate the inertial periods in two locations and the $M 2, S 2$ and $M 4$ periods

\section{2. Tidally versus non-tidally driven models}

\section{2. 1. Ocean currents}

To visualize the velocity field, we present the trajectories of Lagrangian particles in GCOAST35-CRE and GCOAST35-NTE. The particles were released on 1 January 2015 in each grid box of GCOAST7 (GCOAST7 and GCOAST35 grid points partially overlap). The tracking was implemented online for ten days with hourly sampling of the positions. The comparison with the results from GCOAST7 (see Fig. 4 in [15, p. 718]) demonstrates something which is trivial to expect: with about two times finer resolution the eddies in GCOAST35 are about two times smaller than the ones in GCOAST7. 
a)

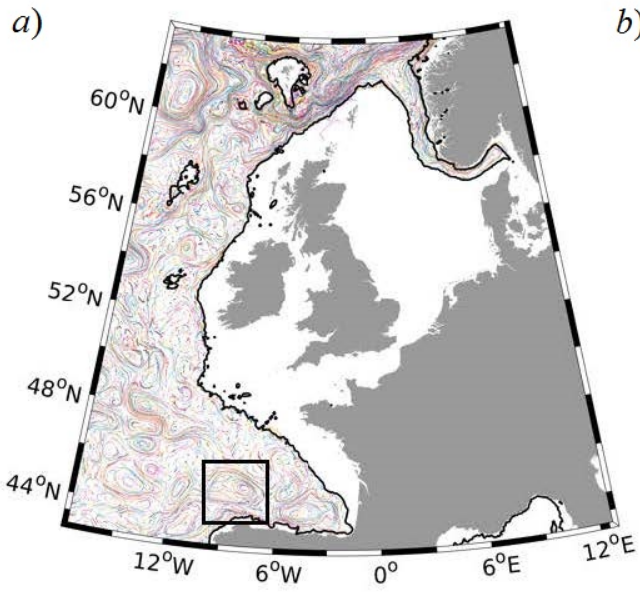

c)

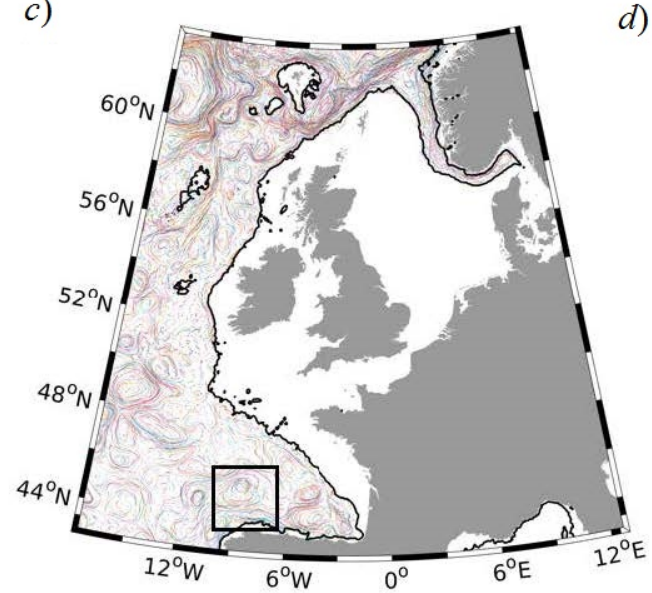

b)

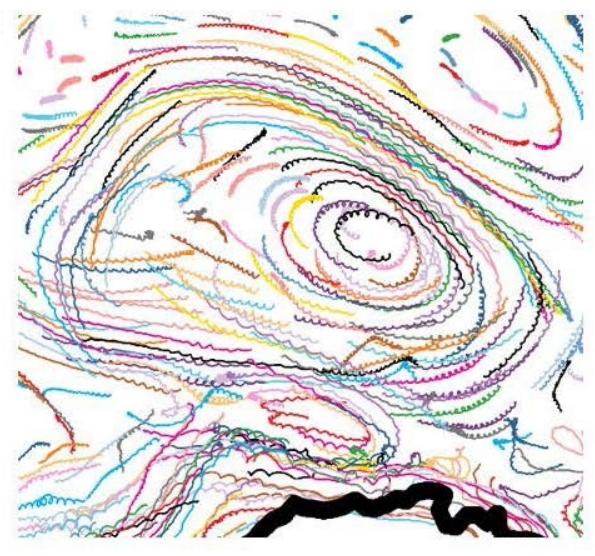

d)

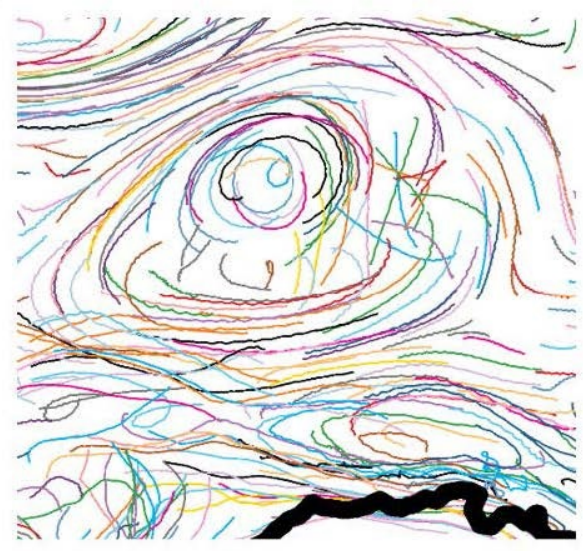

F i g. 5. Velocity is represented as the trajectories of every $5^{\text {th }}$ particle released on January 1,2015 in the GCOAST grid points and tracked over 10 days. $a$ - GCOAST35-CRE; $c$ - GCOAST35-NTE; $b, d-$ the zoomed insets. Different colors for each particle were chosen randomly based on the scheme in [49] to distinguish different trajectories

The eddy field undergoes substantial changes GCOAST35-NTE after 1 January 2014 when the tidal forcing is turned off. However, one year after this change, the scales of the eddies remains almost the same in GCOAST35-CRE and GCOAST35-NTE, as seen in the velocity field at the beginning of 2015 (Fig. 5). The trajectories in the zoomed representations are smoother in the GCOAST35NTE (compare Fig. 5, $b$ and Fig. 5, d). The small loops in the trajectories demonstrate the tidal excursions. The inertial oscillations in GCOAST35-NTE only slightly undulate the trajectories. We will explain in the following whether and how these small tidal displacements affect the ocean circulation.

\section{2. 2. Transient motions}

In the model area, the inertial period ranges between 18.75 and $13.30 \mathrm{~h}$. The tidal maximum disappears in the GCOAST7-NTE and GCOAST35-NTE (Fig. $4 c, d$ ). While the amplitudes of inertial oscillations are slightly lower in 
GCOAST7-NTE than in the GCOAST7-CRE, they are almost the same in GCOAST35-NTE and GCOAST35-CRE. This would suggest that tides do not strongly enhance these oscillations. Similar results are discussed in more detail in [15], see also Fig. 7, $b$ of this study (p. 722).

a)

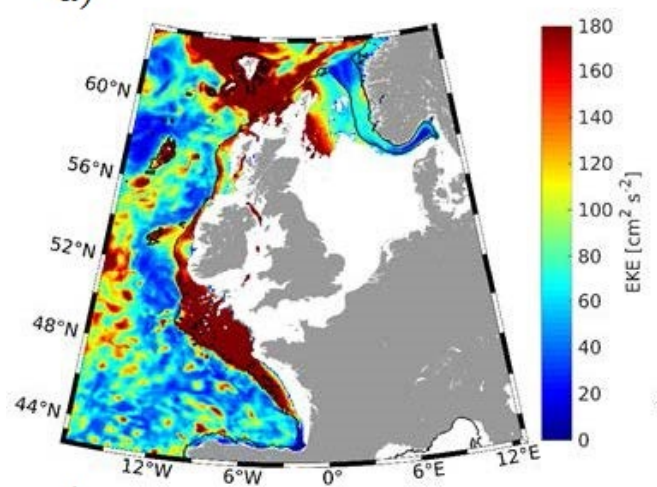

c)

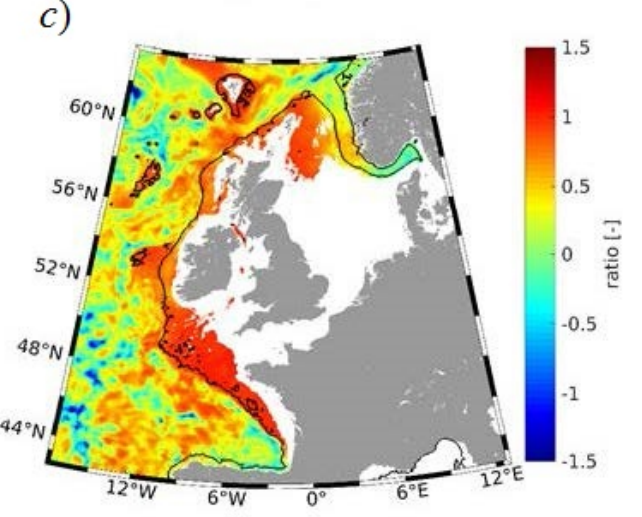

b)

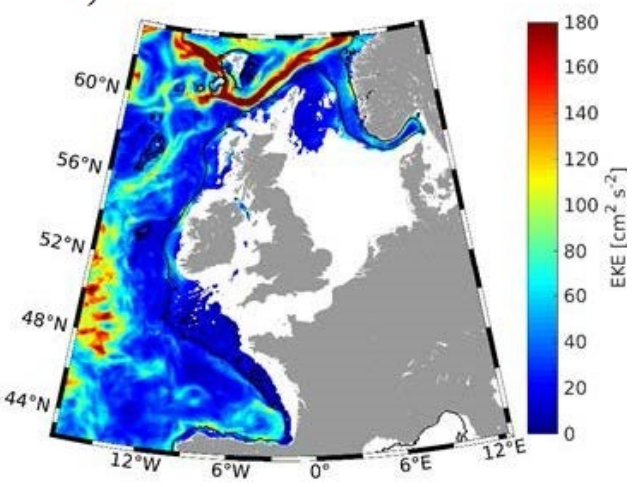

F i g. 6. EKE at the $100 \mathrm{~m}$ depth averaged for January, 1 - December 31, 2015 from GCOAST35$C R E-a$ and GCOAST35-NTE - $b$. Difference between $a$ and $b$ normalized by $a$ is shown in $c$

Because neither GCOAST7, nor GCOAST35 assimilates data, we do not look for an agreement between individual eddies and their positioning and timing, but rather in the statistics of the two models. We define the eddy kinetic energy (EKE) as:

$$
E K E=\frac{\overline{u^{2}}+\overline{v^{2}}}{2}-\frac{\bar{u}^{2}+\bar{v}^{2}}{2}=\frac{\left(\overline{u^{2}}-\bar{u}^{2}\right)+\left(\overline{v^{2}}-\bar{v}^{2}\right)}{2},
$$

where the overbar represents time averaging. This quantity accumulates all types of transient processes (e. g. internal tides, wind-driven variability and mesoscale turbulence). The differences in EKE in the GCOAST35-CRE and GCOAST35NTE (Fig. 6) repeat approximately those shown in Fig. 8 [15, p. 722]. The overall conclusion is that, as far as EKE is concerned, the 7 and $3.5 \mathrm{~km}$ resolution models show almost the same differences (Fig. 6, $c$ ) between cases when tides are included or turned off. The patterns of the EKE in GCOAST7 and GCOAST35 are also very 642 PHYSICAL OCEANOGRAPHY VOL. 27 ISS. 6 (2020) 
similar in the individual experiments. The region most sensitive to barotropic tidal forcing is the shelf of the Biscay Bay and the shallows around the Faroe Islands. This result suggests that mixing over slopes affects the structure of the density field, which is consistent with the study [31]. In the deep ocean, beyond the continental slope, barotropic tides, generally, amplify the mesoscale motion. While the full spectrum of included in the model forcing tidal constituents is responsible for the enhancement of EKE in the deep ocean, it is rather the M2 tide, which explains the larger EKE over the continental slope in the Biscay Bay. This result from the GCOAST35 model is in agreement with the similar conclusion of [15], who used the GCOAST7 model.

\section{3. Wave number spectral analysis}

3. 3. 1. The impact of horizontal resolution: comparison with the data from operational models

The wave number spectra are helpful when analyzing the energy and enstrophy cascades in the inertial subrange [50]. According to the theory of QG turbulence and observations, the $\mathrm{k}^{-5}$ law for SSH is equivalent to the $\mathrm{k}^{-3}$ law for EKE [27]. In the real oceans, the spectral slopes of sea surface height (SSH) computed from altimeter data are flatter than what is predicted by the theory [51, 52].

Explanations of the flattening have been given in [27, 53, 54]. In the area of our study, the spectral flattening has been addressed by [15] with a focus on the role of tides. In Figure 7, wave number spectral characteristics of the four models presented in section 2.1.2 are illustrated along the transects shown in Fig. 1, $b$. These transects are so chosen in order to represent the conditions in the shallow North Sea and in the Bay of Biscay. The inset in Fig. 7, $a$ shows the topographies along these sections. Their lengths are $765 \mathrm{~km}$, which is comparable to what has been used by the authors of [52], who performed a similar analysis.

The mesoscale band, scales of 70-250 km [52], is between the two vertical dashed lines in Fig. 7. As seen by the right-hand side of the spectral lines, which extend to smaller scales, the four models resolve smaller than $70 \mathrm{~km}$ scales, in particular AMM15.

The results from the wave number spectral analysis of the two GCOAST-CRE and the two AMM operational models are presented as solid red and brown lines in Fig. 7. The overall trend is that, in all models, the spectral slopes are largest in the mesoscale range identified by the two vertical dashed lines. The flattening of the spectra at scales smaller than $<70 \mathrm{~km}$ suggests an increasing relative strength of processes in the high-wave number range (e. g., small-scale mixing) compared to the case of pure QG motion [27]. Although the spectral curves show a similar behavior, the energy levels in the individual models differ slightly. The results from the $7 \mathrm{~km}$ resolution models (compare the respective curves in Fig. 7, $a$ and Fig. $7, b$ ) feature a stronger similarity. The brown lines, which correspond to the North Sea closely follow the red lines (deep ocean), demonstrating that the four models forced by barotropic tides act similarly on the shelf. 
a)

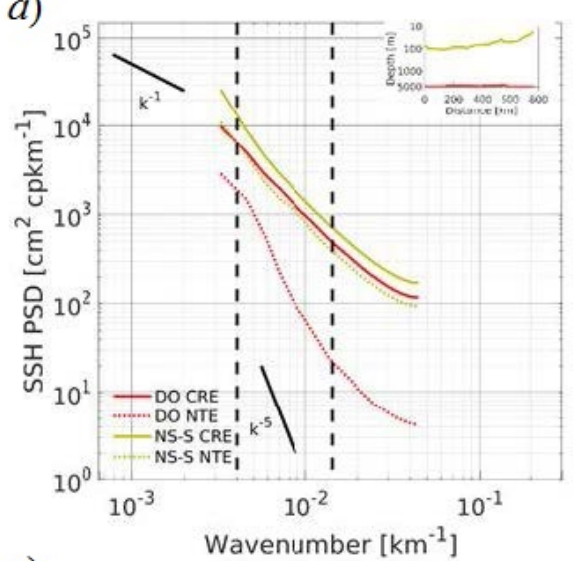

c)

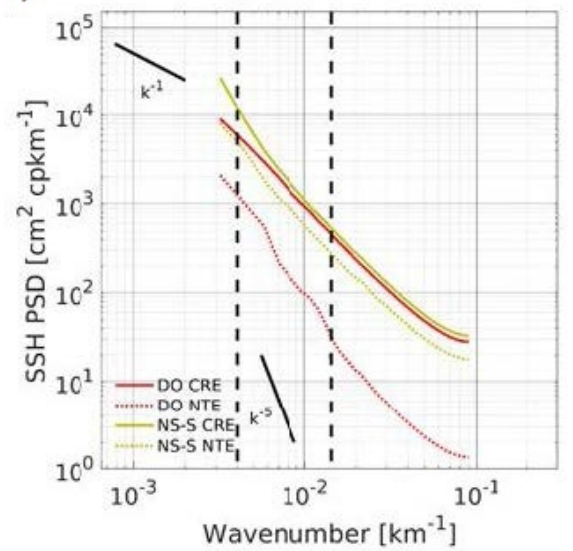

b)

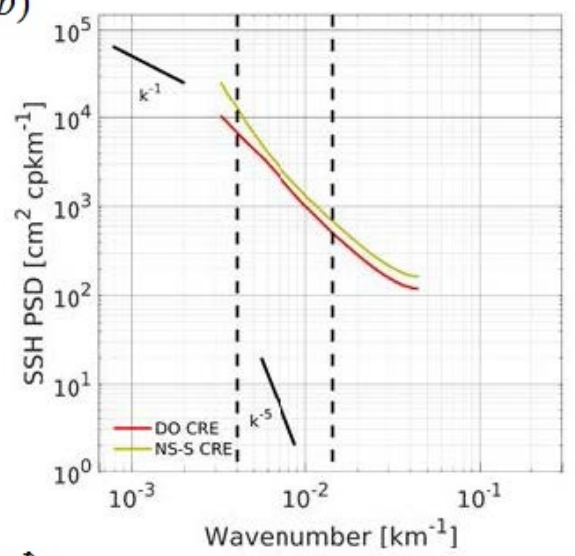

d)

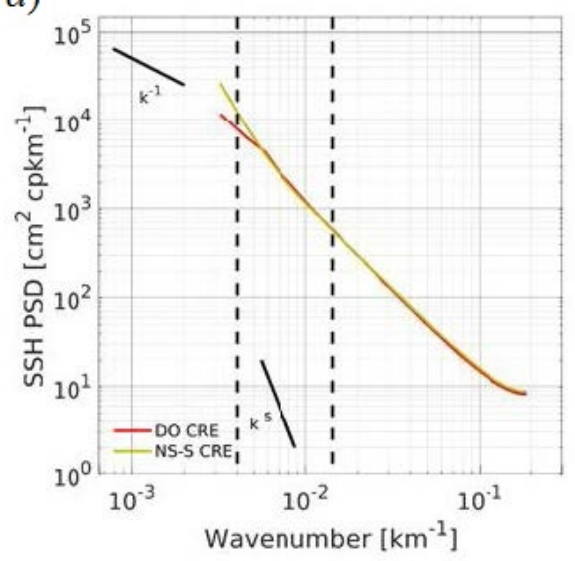

F i g. 7. SSH spectrum along the transect lines in Fig. 1, $b$, averaged over half a year in GCOAST7 $a$, AMM7 - b, GCOAST35 - c, and AMM15 - $d$. Topography along these section lines (from west to east) is shown on the inset in fragment $a$. The abbreviations used are: $D O$ - deep ocean, $N S-S$ - the North Sea shelf. Vertical dashed lines mark the mesoscale range 70-250 km

The interpretation of the results in Fig. 7 can be problematic, as far as the mesoscale motion is concerned, because spectra are subject to rotational (eddies) and potential (internal tides) motions. Notably, the internal tides and mesoscale eddies could have the same horizontal scales. To avoid possible missinterpretation, we analyze the deep-ocean vorticity spectra in CRE and the two operational models represented by the solid lines in Fig. 8. There are some overall similarities in the four models. Flat spectra are characteristic for the large-scale motion. In the mesoscale range, the steepness increases and it reaches the highest values for the smallest motion resolved by the respective model. The slope $\sim \mathrm{k}^{-1}$ is shown because it corresponds to the slope of the QG turbulence. In the $7 \mathrm{~km}$ resolution models this slope is approximately between the scales of 70 to $250 \mathrm{~km}$. The respective range moves toward smaller scales in GCOAST35 and in particular in the AMM15 model. 
a)

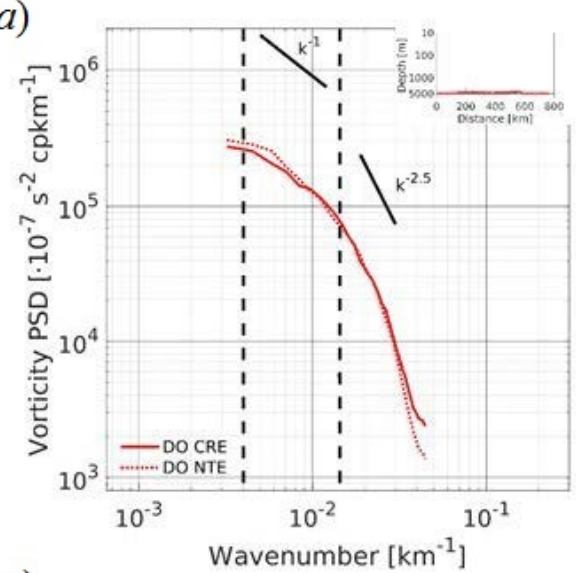

c)

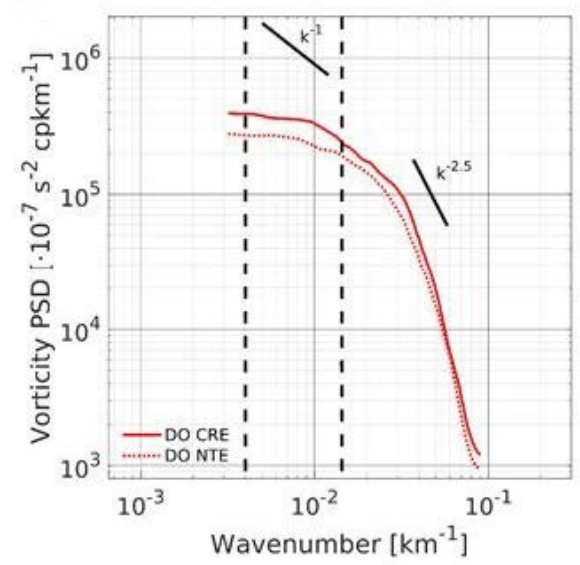

b)

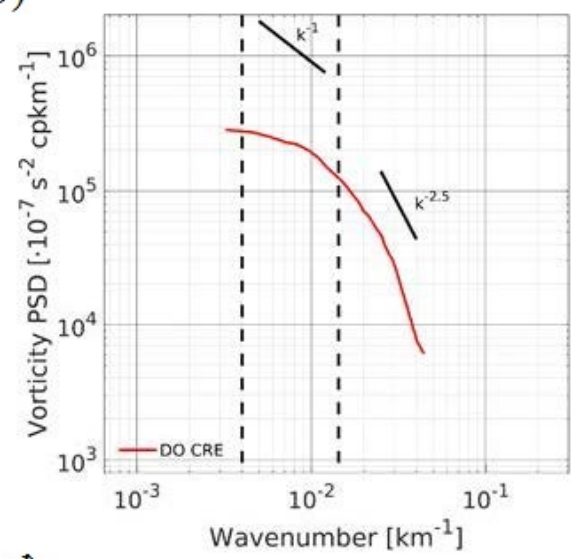

d)

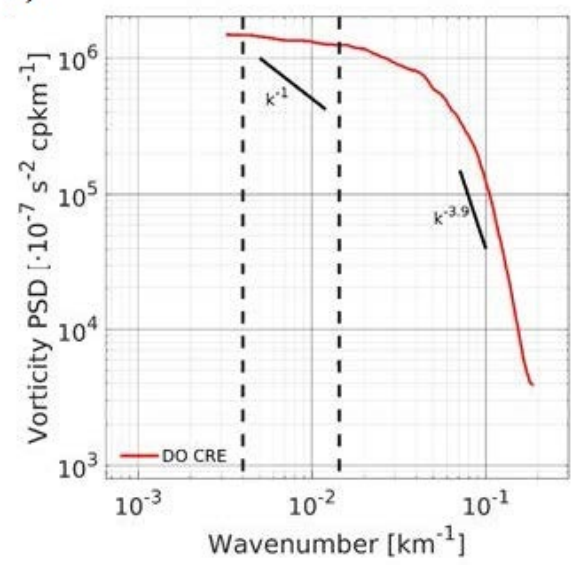

F i g. 8. Vorticity spectrum along the deep ocean transect in Fig. 1, $b$ averaged over half a year in GCOAST7 - $a$, AMM7 - b, GCOAST35 - c, and AMM15 - $d$. Topography along these section lines (from west to east) is shown on the inset in fragment $a$. The legend explains the data used and correspondence (colors) with the section line in Fig. 1, b. DO - deep ocean. Vertical dashed lines mark the mesoscale range from $70-250 \mathrm{~km}$

Several conclusions can be reached. The finer-scale resolution models differ from each other and from the coarser resolution models. The spectra in the AMM7 and GCOAST7 models almost overlap, and that of GCOAST35 is very close to them. However, the level of the rotational signal in AMM15 at scales of $\sim 70 \mathrm{~km}$ is an order of magnitude higher than in the other three models. To find the reason for this discrepancy one needs more technical details about set ups, which are not available to us at the moment. The only important difference we are aware of is that the operational models assimilate data. However, this is perhaps not the reason why AMM15 differs from the other three models. We remind here that the differences in the spectra of GCOAST7 and AMM7 are minor; for these two models data assimilation does not make big difference in spectral characteristics. More probable is that the processes at the small mesoscales and the sub-mesoscale 
processes, which are resolved in AMM15, make the spectral characteristics of the latter so different from the other three models.

\section{3. 2. The impact of tides}

Spectral energy plotted with solid lines (CRE) in Fig. 7, $a, b$ is larger than in NTE (plotted with dotted lines of the same color). This shows that tides tend to increase the spectral power. The spectral slope approaches $\sim \mathrm{k}^{-5}$ by scales of 100-200 $\mathrm{km}$ in the GCOAST7-NTE. The $\mathrm{k}^{-5}$ slope can be considered as a representation of mesoscale turbulence in the inertial subrange. The change of the distance between the spectral curves with the same color with the change of the wave number can be considered as a measure of the role of tides at different scales. This difference normally increases with smaller scales. The flattening of the spectral curves in the range of the small scales follows the regime described in [15]. In GCOAST35-NTE, the spectral slope in the interval 70-200 km is flatter than in the GCOAST7-NTE. The conclusion is that, in the two models, tides flattened substantially the spectral slope, however, this effect is weaker in the GCOAST35 because the NTE curve was already flatter. Obviously, the cascading of energy shows closer similarity to QG turbulence in GCOAST7 than in GCOAST35.

While in the deep ocean turning the tides on flattens the spectrum, the reaction of the shallow ocean is different. In the two models, the respective brown curves have the same slopes, only the energy is slightly reduced in the experiments without tides. This demonstrates that the dynamics on the shelf are actually friction-dominated, therefore the spectral slopes remain almost unchanged with or without tides.

Although the differences in the sea level spectra in the CRE and NTE experiments are quite pronounced, it is not quite clear whether the rotational component of the motion is substantially affected by the barotropic tidal forcing. In order to answer this question we analyze the vorticity spectra, in which the velocity potential associated with the internal tides is excluded. A strong difference between the vorticity spectra in CRE and NTE would represent a strong effect of tides on eddies. At scales smaller than $100 \mathrm{~km}$, the spectral curves in GCOAST7-NTE and GCOAST7-CRE show very small differences (Fig. 8, a). The differences are stronger in the GCOAST35 model, mainly for scales larger than $50 \mathrm{~km}$. The close results in the GCOAST7 and GCOAST35 models suggest that the flattening of the spectra was primarily due to the internal tide (compare Fig. 7, $a$ and Fig. 8, a). The differences between results in the GCOAST35 experiment provide evidence of the increasing effects of barotropic tides on the mesoscale dynamics with increasing model resolution. The overall conclusion from this part of our study is that the variability associated with the rotational motion is also important for spectral flattening at meso-scales. Further regional analyses are needed, along with comparisons with observations, to fully check the reliability of the above results.

\section{Secondary circulation in the Bosporus Strait}

\subsection{Along-channel characteristics of two-layer exchange}

The Strait of Bosporus is a unique oceanographic location where the Black Sea waters (salinity $\sim 17$ to 18 ) meet the Marmara Sea water (salinity 37), 
building salinity gradients of $\sim 20$ in only $\sim 30-40 \mathrm{~km}$ (Fig. 9, $c, d$ ). Two periods, during which we will analyze model simulations, are specified below: between 2831 October 2017 (panels on the left) and 27-30 November 2017 (panels on the right). These periods were dominated by different wind conditions (from the northwest during the first period and from the south, almost parallel to the strait, during the second period). Hereafter, we will be referring to them as outflow and inflow periods, respectively. As known from the study [42], the model response to wind in this shallow strait is quite pronounced. The comparison between the two situations presented in Fig. 9 demonstrates that the salinity front, defined as the position of the bottom salinity isoline 30, displaces to the east (east of the bottom trench situated at $\sim$ km 22) during the inflow event. This frontal zone propagates on the Black Sea shelf as a very thin gravity plume. The opposite extreme case was caused by the northwest wind, which pushed the front toward the Marmara Sea. After the wind speed decreases, the saltier Marmara Sea water propagates along the channel as in lock exchange experiments. Similar variability occurs at all times, as shown in Fig. 12 of [42, p. 1020], where the results of the numerical model used here are compared against the observations of [55]. The surface current in the outflow period (directed to the south) is rather strong between the trench and the southern sill (Fig. 9, a). The "rough" zero-velocity interface suggest an entrainment of the Marmara Sea water by the surface flow.

a)

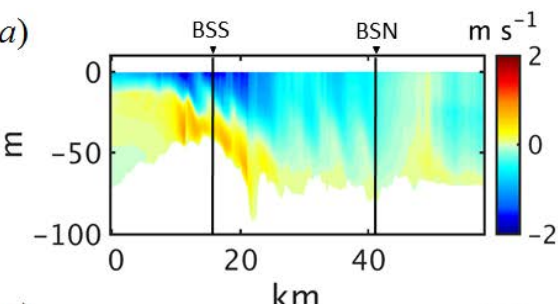

c)

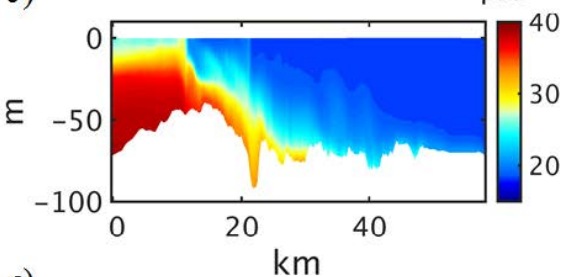

e)

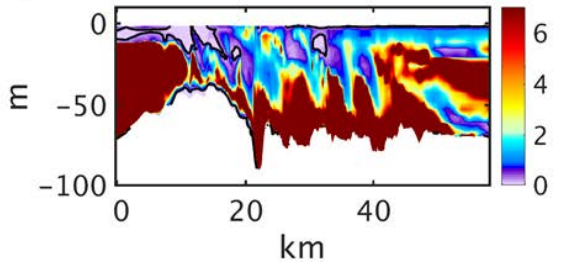

b)

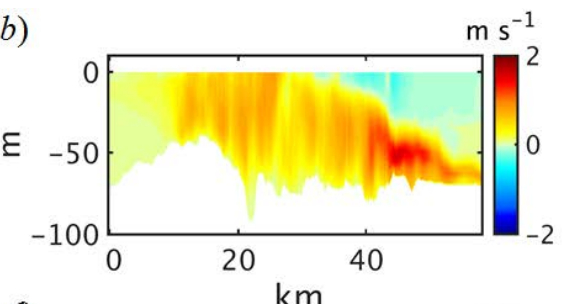

d)

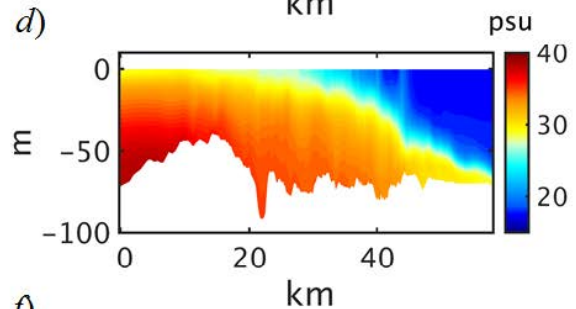

f)

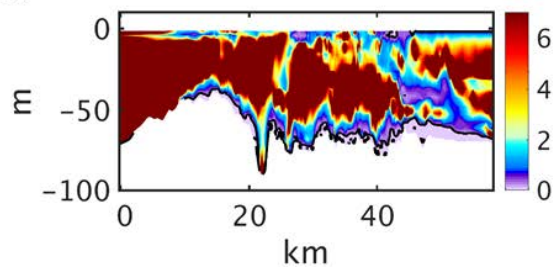

F i g. 9. Vertical transects along the Bosporus Strait (black line in Fig. 2, b) of the along-channel velocity $-a, b$, salinity $-c, d$ and the Richardson number $-e, f$ during the outflow event (October 28$31,2017)$ - on the left and the inflow event (November 27-30, 2017) - on the right. Vertical black lines in fragment $a$ show positions of the across-channel sections represented in Figs. 10 and 11 
The two situations shown in Fig. 9 represent cases when either the upper or lower layer flow is blocked. The strong outflow situation is characterized by an increase of the slope of the salinity front and larger entrainment at the interface. The gradient Richardson number

$$
R i=-\frac{g}{\rho_{0}} \frac{\partial \rho}{\partial z} /\left(\frac{\partial u}{\partial z}\right)^{2},
$$

which quantifies the competition between the stabilizing effect of density stratification and the destabilizing effect of velocity shear (Fig. 9, $e, f$ ) shows a very different structure during the two situations. The isoline $\mathrm{Ri}=0.25$, is the critical value, below which the flow becomes unstable. Values lower than the critical value occur mostly in the bottom layer during strong inflow conditions (Fig. 9, f). By dominant outflows, the upper part of the water column is destabilized, primarily between the sill in the southern part of the strait and the sill at the northern exit of the strait (approximately at $\mathrm{km} \mathrm{42)}$ ). Between the two sills, Ri features an increased surface layer thickness and strong interfacial mixing. This behavior is similar to what happens in the Baltic Sea straits [14]. Obviously, the two strait systems are similar to each other and different from the tidal estuaries. Contrary to what happens in tidal estuaries, vertical mixing increases in the straits during outflow situations. The reasons for that are explained in the above-cited work.

\section{2. Across-channel characteristics of the two-layer exchange}

Two across-channel sections, one in the southern part of the strait (Fig. 10) and one in its northern part (Fig. 11) will be used to illustrate the vertical distribution of the basic characteristics of channel's hydrodynamics. We will refer to these sections as to Bosporus Strait South (BSS) and Bosporus Strait North (BSN). Their positions are shown in Fig. 2, $b$ and in Fig. 9, $a$. For the reader, the view point is south in Figs. 10, 11, that is the western shore is on the left side and the eastern shore on the right. During the outflow phase (panels on the left in Fig. 10 and Fig. 11), saltier Marmara Sea water is pushed southward by the brackish Black Sea water. Most of the water column on the southern section (Fig. 10, c) and the entire water column on the northern section (Fig. 11, c) feature low salinity, the sharpest salinity gradient occurs at km 10-15 (Fig. 9). The Marmara Sea water in this period appears only in the bottom layers of BSS (Fig. 10, c). The difference between salinities at the two sections gives a nice illustration of the mixing between the surface and bottom waters along the channel, which results in an almost vanishing signal of Marmara Sea water at BSN.

The inflow shows a completely opposite salinity distribution (Fig. 10, $d$ and Fig. 11, d) with salty Marmara Sea water filling the entire BSS section but only the layers below 25-30 m at BSN. Above $20 \mathrm{~m}$, the mixed Black Sea water flows southward (Fig. 11, $b$ ).

The velocity shear is quite different during the two situations, and varies along the channel. Axial flow on the southern section is two-layered during outflow conditions (Fig. 10,a). On the BSN section, the current tends to reverse direction only very close to the bottom (Fig. 11, a), and its magnitude is very small 
compared to the magnitude of the bottom current at BSS. This demonstrates the strong overturning of flow along the strait. The correlation between salinity and axial flow is very high, in particular at BSS, which is reminiscent of the mean estuarine circulation. Similarly, the correlation between salinity and current is very clear in the northern section during inflow conditions (compare Fig. 11, $b$ and Fig. 11, d). The across-channel asymmetry in the pattern of axial velocity is very clear during inflow conditions (Fig. 10, b) when the core of the flow is displaced to the right (the eastern coast of the Bosporus Strait).
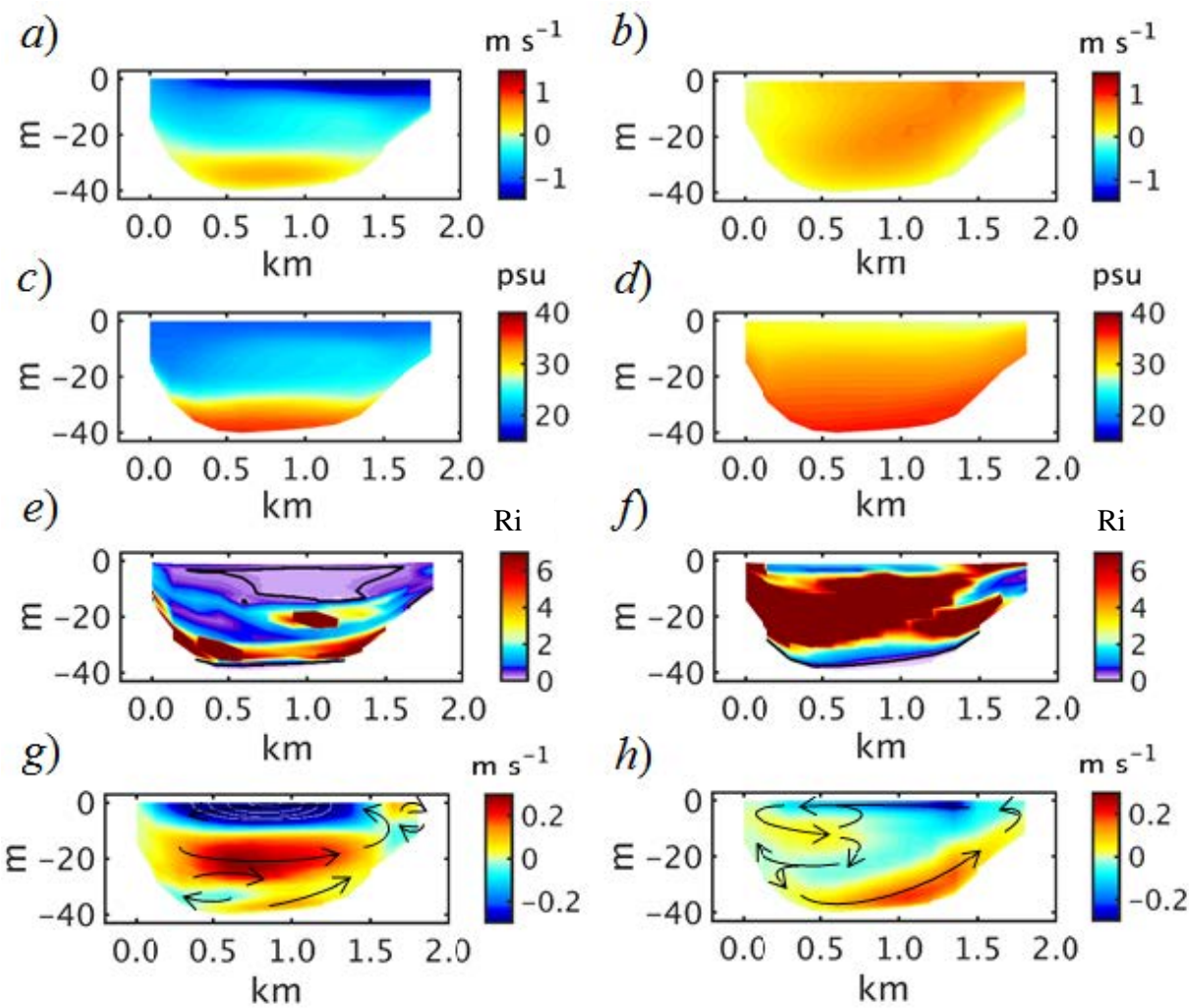

F i g. 10. Axial velocity $-a, b$, salinity $-c, d$, the Richardson number $-e, f$, and lateral velocity $-g, h$ at the BSS section in the Bosporus Strait (see its location in Figs. 2, $b$ and 9, $a$ ) averaged under the outflow conditions (October 28-31, 2017) - on the left and the inflow conditions (November 27-30, 2017) - on the right. Positive axial velocities indicate the inflow (from the saltier side towards the fresher one), and negative values indicate the outflow in the opposite direction. White contour lines in fragment $g$ mark the range from -0.7 to $-0.4 \mathrm{~m} \cdot \mathrm{s}^{-1}$ with the $0.1 \mathrm{~m} \cdot \mathrm{s}^{-1}$ step

The variability of $\mathrm{Ri}$ in the Bosporus Strait (Fig. 10, e, $f$ and Fig. 11, e, $f$ ) shows similarities to findings in the Baltic Sea straits [14]. As explained on the example of the along-channel properties, the Richardson number is overall lower during the outflow phase than during the inflow phase. This is apparent along the entire across-channel section (compare Fig. 10, $e$ and Fig. 10, f), and is in contradiction to the tidal straining in estuaries [56]. It seems evident that the less saline surface inflow cannot provide enough stabilization to compensate the effect 
of the velocity shear. This demonstrates that in shallow ocean straits the changes of two-layer flow due to atmospheric variability are fundamentally different from the straining of isopycnals in estuarine environments caused by tides. What makes the Black Sea case interesting is that the outflow conditions are characterized by two layers of maximum Ri (e. g., Fig. 10, e). A similar maximum at $~ 20$ m occurs also during inflow conditions (Fig. 11,e). It follows that the competition between the stabilizing effect of salinity stratification and the destabilizing effect of velocity shear features a complex vertical pattern. It is notable that the areas where $\mathrm{Ri}<0.25$ are at the sides of the narrow channel during the inflow case (Fig. 11, e).

a)

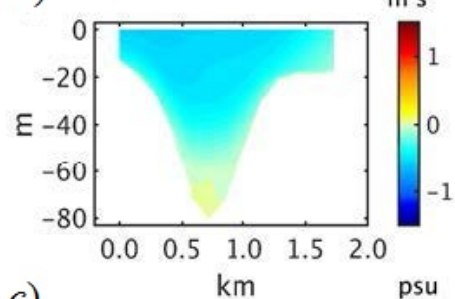

c)

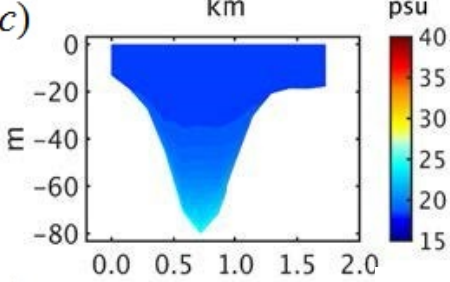

e)

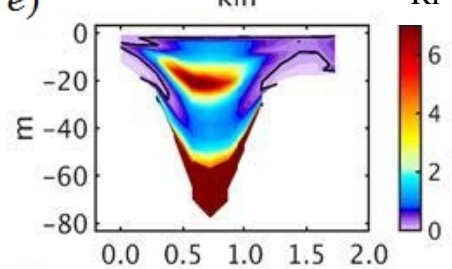

g)

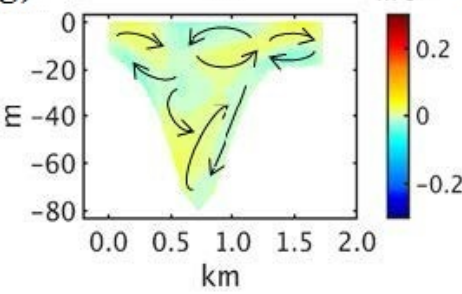

b)
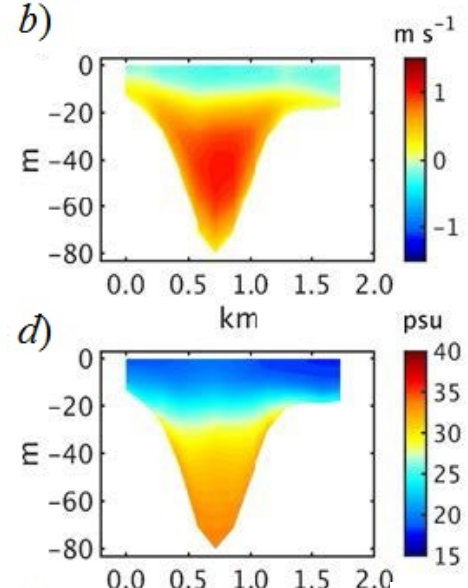

f)

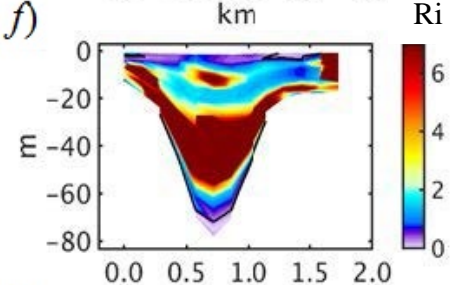

h)

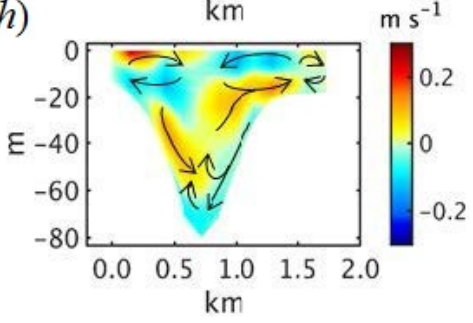

F i g. 11. Axial velocity $-a, b$, salinity $-c$, $d$, the Richardson number $-e$, $f$, and lateral velocity $-g, h$ at the BSN section in the Bosporus Strait (see its location in Figs. 2, $b$ and 9, $a$ ) averaged under the outflow conditions (October 28-31, 2017) - on the left and the inflow conditions (November 2730,2017 ) - on the right. Positive axial velocities indicate the inflow (from the saltier side towards the fresher one), and negative values indicate the outflow in the opposite direction

The relative importance of the individual driving terms in the momentum equation governing the secondary circulation in straits was addressed in [14] on the Baltic Sea example. Here, we will just shortly review how these terms affect the 
motion. In curved channels, inertial forces can strongly affect the dynamics; their impact is negligible in an ideally straight channel. As demonstrated by [57], the acceleration due to the streamwise advection of lateral momentum is very important, where abrupt changes in curvature occur. The acceleration due to lateral density gradients occurs because velocities in the center of the channel exceed those in near-shore area. In consequence, the along-stream density gradient is translated into lateral density gradients, which explains the formation of counterrotating secondary circulation cells. The Coriolis deflection of streamwise flow becomes increasingly important with the increase of the channel width [58], leading to the formation of a single-cell secondary circulation. The last term is due to friction, which is balancing the former four driving terms. The combination of these terms explains the spatial characteristics of secondary flow.

In the following, we discuss the different appearances of the helical secondary circulation cells at BSS and BSN sections (Fig. 10, $g, h$ and Fig. 11, $g, h$ ). The lateral velocity is presented positive if directed towards the eastern shore and negative when directed towards the western shore. The outflow situation at the southern section shows extremely large magnitudes of the lateral flow exceeding $0.5 \mathrm{~m} / \mathrm{s}$ in the $5-10 \mathrm{~m}$ thick surface layer. This is comparable with the magnitude of the axial flow. The maximum of the counter-current occurs at $\sim 20 \mathrm{~m}$, thus the major cell of secondary circulation is anticlockwise. Two small clockwise circulation cells develop at the Asian side (at shallow depths) and at the European side (at the bottom).

The inflow conditions reveal a less contrasting layering in the vertical (Fig. 10, h) and the overall structure is roughly one large anticlockwise cell. This cell is most pronounced near the eastern coast, which is in agreement with the pattern of the axial flow (Fig. 10, b). This type of circulation pattern suggests a dominance of the Coriolis force. Along the European coast, three circulation cells, one above the other, appear embedded in the larger-scale anticlockwise cell.

The lateral velocities at BSN are substantially lower than at BSS, in particular during the outflow situation. A system of multiple weak circulation cells occurs at BSN, in the top $20 \mathrm{~m}$, during both periods (Fig. 11, $g, h$ ). The overall structure of surface helixes is similar in the two situations, however the magnitudes of the lateral currents are substantially larger during inflow. In the deeper layers, the patterns are also qualitatively similar. It is evident that the overturning of the water masses in the Bosporus is not only associated with entrainment at the interface between the upper and lower currents. The secondary circulation contributes strongly to this overturning.

Between the two sections, there are two major differences in the helical cells. The first is that at the BSS section, the cells have larger scales; the second is that the lateral velocity during outflow conditions is approximately three times stronger at the BSS section. The finding that the magnitude of lateral current is comparable to that of the axial current could suggest that the helical cells at the BSS section are enhanced by the wind. The comparison with the situation at the BSN section disqualifies this hypothesis because the wind does not change substantially at these small scales, nevertheless no such strong lateral currents occur and the BSN. Furthermore, at the BSS section, the direction of the lateral surface current (Fig. 10, g) opposes the west-wind component. It is more plausible that PHYSICAL OCEANOGRAPHY VOL. 27 ISS. 6 (2020) 
the complex vertical structure of the two-layer flow depends on the channel bathymetry, the varying salinity gradients, as well as the action of wind along the entire length of the strait.

There is not a full analogy between the inflow and outflow situations in the Bosporus Strait and those in the straits connecting the Baltic Sea and the North Sea [14]. In the latter case, the qualitative differences between lateral circulation by the inflow and outflow phases is more pronounced in comparison with the case of the Bosporus Strait. However, there is one important similarity. In both strait systems, helical circulations have scales of $\sim 1 \mathrm{~km}$, even less at the BSN section. To resolve them, we need a horizontal resolution below $100 \mathrm{~m}$, i.e. to go to sub mesoscales. This has not been achieved in earlier models of basins connected by very narrow straits, which could have largely affected their performance in reproducing an adequate two-layer exchange. There appears an interesting analogue between ocean models resolving mesoscale eddies and models for ocean straits resolving the secondary circulation. As recognized by [14], the failure to resolve the secondary circulation in the straits appears similar to the problems caused by the failure to resolve mesoscale eddies in ocean models.

\section{Conclusions}

This study addresses the rotational motion of geophysical fluids in the horizontal and vertical plane. Ocean eddies are taken as an example of the first type of motion, while the dynamics of channel flows, as seen in the results of numerical simulations, are analyzed as a representative of the rotational motion in the vertical plane.

The results of four NEMO set ups for the European North West shelf are analyzed. Two of them are operational models, the other two are used as instruments to perform sensitivity studies. The analysis of numerical simulations is focussed on the dynamical coupling between the barotropic tides and eddies. A major issue is the robustness of the results in dependence on the model resolution.

The secondary circulation in ocean straits was resolved with a horizontal grid of $\sim 100 \mathrm{~m}$, i.e. the experiments fully resolved the sub-mesoscale motion. We demonstrate that, with this ultra-fine model resolution, new elements of physical motion in the straits emerged in the simulation.

The intercomparison of four NEMO models with resolutions ranging from 7 to $1.5 \mathrm{~km}$ showed that the simulations are realistic. The major dynamical difference in the experiments driven with or without tidal forcing is that, in the latter, the inertial motion is providing most of the variability at high frequencies. It was found that the tidal motion did not transfer a substantial amount of energy to the inertial motion (the magnitude of inertial oscillations remained almost the same in GCOAST35-NTE and GCOAST35-CRE). The shelf of the Biscay Bay and the shallows around the Faroe Islands are the most sensitive areas affected by the addition of barotropic tides to the forcing. The slopes of the spectral curves in the GCOAST7 model were higher in the experiment without tides, approaching a slope that is known from the theory of QG turbulence. The corresponding effect is weaker in the GCOAST35 model because, even without tides, the slope of the spectral curve is flatter. This indicates that with increasing resolution 
the mixing tends to increase, thus reducing the overall effect of tidal flattening. One can conclude that the GCOAST7 model shows more similarity to QG turbulence than the GCOAST35 model.

The most significant difference between the spectral properties of the four models occurs in the analysis of the rotational component of motion. Two important results can be identified: (1) the magnitude of the vorticity power spectral density at scales of $\sim 70 \mathrm{~km}$ is an order of magnitude higher in the AMM15 than in the other studied models (AMM15 partially resolves submesoscale processes), and (2) the comparison between GCOAST7 and GCOAST35 shows that beyond a certain horizontal resolution, the internal tides tend to substantially affect the properties of wave number spectra. This provides an evidence of the increasing impact of barotropic tides on the mesoscale dynamics with increasing model resolution. Of particular interest is the change of model physics as seen in the spectral properties of AMM15, the only one of the three considered models, which resolves small mesoscale and the sub-mesoscale processes.

The dynamics of outflows in straits are strongly dependent on the Richardson number measuring the stabilizing effect of density stratification against the destabilizing effect of velocity shear. The analysis of this number reveals strong interfacial mixing in the area between the southern and northern sills of the Bosporus. Contrary to what happens in tidal estuaries, the vertical mixing increases in the straits during outflow situations. This characteristic of the Bosporus Strait is similar to what is known for the Baltic Sea straits. It appears that the less saline surface water cannot provide enough stabilization to compensate the effect of velocity shear. This suggests that, in the straits, the variability of the two-layer flow caused by mechanical forcing (wind) is fundamentally different from the straining of isopycnals in estuarine environments caused by tides (also a mechanical forcing).

The lateral sections feature systems of multiple circulation cells with scales of $\sim 1 \mathrm{~km}$. The magnitude of the lateral flow during outflow situation at the southern section are extremely large, exceeding $0.5 \mathrm{~m} / \mathrm{s}$ in the $5-10 \mathrm{~m}$ thick surface layer. This is comparable with the magnitude of the axial flow, which illustrates the importance of the helical elements of the strait's circulation for the entrainment at the interface separating the surface and bottom flows. Evidently, the overturning of the water masses in the Bosporus Straits is promoted by the secondary circulation. The overall structure of helical cells is similar in the inflow and outflow situations. In this, the Bosporus differs from the straits connecting the Baltic Sea and the North Sea. In the latter case, the qualitative differences between lateral circulation by the inflow and outflow phases are more pronounced. The dynamical elements described above appear only if we resolve the strait with a horizontal resolution below $100 \mathrm{~m}$ using a seamless numerical model based on unstructured grids. This has not been achieved previously in models of basins connected through very narrow straits. Missing these sub-mesoscale elements of strait circulation could have significantly affected the earlier model-representations of the two-layer exchange flows. We find an instructive analogy between ocean models resolving mesoscale eddies (rotation in a horizontal plane) and models including ocean straits resolving the secondary circulation (rotation in a vertical 
plane). Without the helical cells, the models do permit two-layer exchange, but do not resolve it. Without appropriate resolution, ocean models permit simulating the large-scale flows, but not the correct energy cascades at eddy scales.

\section{REFERENCES}

1. Mossa, M., 2021. The Recent 500th Anniversary of Leonardo da Vinci’s Death: a Reminder of his Contribution in the Field of Fluid Mechanics. Environmental Fluid Mechanics, 21, pp. 1-10. https://doi.org/10.1007/s10652-020-09748-4

2. Helmholtz, H., 2009. Über Integrale der hydrodynamischen Gleichungen, welche den Wirbelbewegungen entsprechen. Journal fur die Reine und Angewandte Mathematik, 1858(55), pp. 25-55. https://doi.org/10.1515/crll.1858.55.25

3. Monin, A.S., Kamenkovich, V.M. and Kort, V.G., 1977. Variability of the Oceans. London: John Wiley \& Sons Ltd, 241 p.

4. Kamenkovich, V.M., Koshlyakov, M.N. and Monin, A.S., Eds., 1986. Synoptic Eddies in the Ocean. Dordrecht, Holland: D. Reidel Publishing Company, 433 p.

5. The MODE Group, 1978. The Mid-Ocean Dynamics Experiment. Deep Sea Research, 25(10), pp. 859-910. https://doi.org/10.1016/0146-6291(78)90632-X

6. McWilliams, J.C., Owens, W.B. and Hua, B.L., 1986. An Objective Analysis of the POLYMODE Local Dynamics Experiment. Part I: General Formalism and Statistical Model Parameters. Journal of Physical Oceanography, 16(3), pp. 483-504. doi:10.1175/15200485(1986)016<0483:AOAOTP>2.0.CO;2

7. Semtner, A.J. and Chervin, R.M., 1992. Ocean General Circulation from a Global EddyResolving Model. Journal of Geophysical Research, 9(C4), pp. 5493-5550. https://doi.org/10.1029/92JC00095

8. Malone, R.C., Smith, R.D., Maltrud, M.E. and Hecht, M.W., 2003. Eddy-Resolving Ocean Modeling. Los Alamos Science, 28, pp. 223-231.

9. Maltrud, M.E. and McClean, J.L., 2005. An Eddy Resolving Global 1/10 ${ }^{\circ}$ Ocean Simulation. Ocean Modelling, 8(1-2), pp. 31-54. doi:10.1016/j.ocemod.2003.12.001

10. Treguier, A.M., Deshayes, J., Le Sommer, J., Lique, C., Madec, G., Penduff, T., Molines, J.-M., Barnier, B., Bourdalle-Badie, R. and Talandier, C., 2014. Meridional Transport of Salt in the Global Ocean from an Eddy-Resolving Model. Ocean Science, 10, pp. 243-255. https://doi.org/10.5194/os-10-243-2014

11. Iovino, D., Masina, S., Storto, A., Cipollone, A. and Stepanov, V.N., 2016. A 1/16² Eddying Simulation of the Global NEMO Sea-Ice-Ocean System. Geoscientific Model Development, 9(8), pp. 2665-2684. https://doi.org/10.5194/gmd-9-2665-2016

12. Robinson, A.R., Harrison, D.E. and Haidvogel, D.B., 1979. Mesoscale Eddies and General Ocean Circulation Models. Dynamics of Atmospheres and Oceans, 3(2-4), pp. 143-180. https://doi.org/10.1016/0377-0265(79)90005-8

13. McWilliams, J.C., 2016. Submesoscale Currents in the Ocean. Proceedings of the Royal Society A. Mathematical, Physical and Engineering Sciences, 472(2189), 20160117. http://doi.org/10.1098/rspa.2016.0117 
14. Haid, V., Stanev, E.V., Pein, J., Staneva, J. and Chen, W., 2020 . Secondary Circulation in Shallow Ocean Straits: Observations and Numerical Modeling of the Danish Straits. Ocean Modelling, 148, 101585. https://doi.org/10.1016/j.ocemod.2020.101585

15. Stanev, E.V. and Ricker, M., 2020. Interactions between Barotropic Tides and Mesoscale Processes in Deep Ocean and Shelf Regions. Ocean Dynamics, 70, pp. 713-728. https://doi.org/10.1007/s10236-020-01348-6

16. Madec, G. and the NEMO team, 2008. NEMO Ocean Engine. Note du Pôle de modélisation. Technical Report. France: Institut Pierre-Simon Laplace, no. 27. Available at: https://www.nemo-ocean.eu/doc/node1.html [Accessed: 5 November 2020]. 386 p.

17. Lerczak, J.A. and Geyer, W.R., 2004. Modeling the Lateral Circulation in Straight, Stratified Estuaries. Journal of Physical Oceanography, 34(6), pp. 1410-1428. https://doi.org/10.1175/1520-0485(2004)034<1410:MTLCIS>2.0.CO;2

18. Zhang, Y.J., Ye, F., Stanev, E.V. and Grashorn, S., 2016. Seamless Cross-Scale Modeling with SCHISM. Ocean Modelling, 102, pp. https://doi.org/10.1016/j.ocemod.2016.05.002

19. Di Fidio, M. and Gandolfi, C., 2011. Flow Velocity Measurement in Italy between Renaissance and Risorgimento. Journal of Hydraulic Research, 49(5), pp. 578-585. doi:10.1080/00221686.2011.594599

20. Lelong, M.-P. and Kunze, E., 2013. Can Barotropic Tide-Eddy Interactions Excite Internal Waves? Journal of Fluid Mechanics, 721, pp. 1-27. https://doi.org/10.1017/jfm.2013.1

21. Rocha, C.B., Chereskin, T.K., Gille, S.T. and Menemenlis, D., 2016. Mesoscale to Submesoscale Wavenumber Spectra in Drake Passage. Journal of Physical Oceanography, 46(2), pp. 601-620. https://doi.org/10.1175/JPO-D-15-0087.1

22. Morozov, E.G., 1995. Semidiurnal Internal Wave Global Field. Deep-Sea Research Part I: Oceanographic Research Papers, 42(1), pp. 135-148. https://doi.org/10.1016/09670637(95)92886-C

23. Ray, R.D. and Mitchum, G.T., 1997. Surface Manifestation of Internal Tides in the Deep Ocean: Observations from Altimetry and Island Gauges. Progress on Oceanography, 40(1-4), pp. 135-162. https://doi.org/10.1016/S0079-6611(97)00025-6

24. Egbert, G.D. and Ray, R.D., 2001. Estimates of $\mathrm{M}_{2}$ Tidal Energy Dissipation from TOPEX/Poseidon Altimeter Data. Journal of Geophysical Research: Oceans, 106(C10), pp. 22475-22502. https://doi.org/10.1029/2000JC000699

25. Vlasenko, V., Stashchuk, N. and Hutter, K., 2005. Baroclinic Tides: Theoretical Modeling and Observational Evidence. Cambridge: Cambridge University Press, 372 p.

26. Garrett, C. and Kunze, E., 2007. Internal Tide Generation in the Deep Ocean. Annual Review of Fluid Mechanics, 39, pp. 57-87. https://doi.org/10.1146/annurev.fluid.39.050905.110227

27. Richman, J.G., Arbic, B.K., Shriver, J.F., Metzger, E.J., and Wallcraft, A.J., 2012. Inferring Dynamics from the Wavenumber Spectra of an Eddying Global Ocean Model with Embedded Tides. Journal of Geophysical Research: Oceans, 117(C12), C12012. https://doi.org/10.1029/2012JC008364

28. Savage, A.C., Arbic, B.K., Richman, J.G., Shriver, J.F., Alford, M.H., Buijsman, M.C., Farrar, J.T., Sharma, H., Voet, G., Wallcraft, A.J. and Zamudio, L., 2017. Frequency Content of Sea Surface Height Variability from Internal Gravity Waves to Mesoscale Eddies. Journal 
of Geophysical Research: Oceans, 122(3), pp. 2519-2538. https://doi.org/10.1002/2016JC012331

29. Tchilibou, M., Gourdeau, L., Morrow, R., Serazin, G., Djath, B. and Lyard, F., 2018. Spectral Signatures of the Tropical Pacific Dynamics from Model and Altimetry: a Focus on the Meso/Submesoscale Range. Ocean Science, 14(5), pp. 1283-1301. https://doi.org/10.5194/os-141283-2018

30. Huthnance, J.M., 1995. Circulation, Exchange and Water Masses at the Ocean Margin: the Role of Physical Processes at the Shelf Edge. Progress in Oceanography, 35(4), pp. 353-431. https://doi.org/10.1016/0079-6611(95)00012-6

31. Huthnance, J.M., Holt, J.T. and Wakelin, S.L., 2009. Deep Ocean Exchange with West-European Shelf Seas. Ocean Science, 5(4), pp. 621-634. https://doi.org/10.5194/os-5-621-2009

32. Buckingham, C.E., Naveira Garabato, A.C., Thompson, A.F., Brannigan, L., Lazar, A., Marshall, D.P., George Nurser, A.J., Damerell, G., Heywood, K.J. and Belcher, S.E., 2016. Seasonality of Submesoscale Flows in the Ocean Surface Boundary Layer. Geophysical Research Letters, 43(5), pp. 2118-2126. https://doi.org/10.1002/2016GL068009

33. Hallberg, R., 2013. Using a Resolution Function to Regulate Parameterizations of Oceanic Mesoscale Eddy Effects. Ocean Modelling, 72, pp. 92-103. https://doi.org/10.1016/j.ocemod.2013.08.007

34. Polton, J.A., 2015. Tidally Induced Mean Flow over Bathymetric Features: a Contemporary Challenge for High-Resolution Wide-Area Models. Geophysical \& Astrophysical Fluid Dynamics, 109(3), pp. 207-215. https://doi.org/10.1080/03091929.2014.952726

35. Holt, J., Hyder, P., Ashworth, M., Harle, J., Hewitt, H.T., Liu, H., New, A.L., Pickles, S., Porter, A. [et al.], 2017. Prospects for Improving the Representation of Coastal and Shelf Seas in Global Ocean Models. Geoscientific Model Development, 10(1), pp. 499-523. https://doi.org/10.5194/gmd-10-499-2017

36. Guihou, K., Polton, J., Harle, J., Wakelin, S., O'Dea, E. and Holt, J., 2017. Kilometric Scale Modeling of the North West European Shelf Seas: Exploring the Spatial and Temporal Variability of Internal Tides. Journal of Geophysical Research: Oceans, 123(1), pp. 688-707. https://doi.org/10.1002/2017JC012960

37. Graham, J.A., Rosser, J.P., O'Dea, E. and Hewitt, H.T., 2018. Resolving Shelf Break Exchange around the European Northwest Shelf. Geophysical Research Letters, 45(22), pp. 12386-12395. https://doi.org/10.1029/2018GL079399

38. Tonani, M., Sykes, P., King, R.R., McConnell, N., Péquignet, A.-C., O'Dea, E., Graham, J.A., Polton, J. and Siddorn, J., 2019. The Impact of a New High-Resolution Ocean Model on the Met Office North-West European Shelf Forecasting System. Ocean Science, 15(4), pp. 11331158. https://doi.org/ 10.5194/os-15-1133-2019

39. O’Dea, E.J., Arnold, A.K., Edwards, K.P., Furner, R., Hyder, P., Martin, M.J., Siddorn, J.R., Storkey, D., While, J., Holt, J.T. and Liu, H., 2012. An Operational Ocean Forecast System Incorporating NEMO and SST Data Assimilation for the Tidally Driven European North-West Shelf. Journal of Operational Oceanography, 5(1), pp. 3-17. https://doi.org/10.1080/1755876X.2012.11020128

40. Ho-Hagemann, Ha T.M., Hagemann, S., Grayek, S., Petrik, R., Rockel, B., Staneva, J., Feser, F. and Schrum, C., 2020. Internal Model Variability of the Regional Coupled System Model GCOASTAHOI. Atmosphere, 11(3), 227. https://doi.org/10.3390/atmos11030227 
41. Egbert, G.D. and Erofeeva, S.Y., 2002. Efficient Inverse Modeling of Barotropic Ocean Tides. Journal of Atmospheric and Oceanic Technology, 19(2), pp. 183-204. doi:10.1175/1520-0426(2002)019<0183:EIMOBO>2.0.CO;2

42. Stanev, E.V., Grashorn, S. and Zhang, Y.J., 2017. Cascading Ocean Basins: Numerical Simulations of the Circulation and Interbasin Exchange in the Azov-Black-MarmaraMediterranean Seas System. Ocean Dynamics, 67(8), pp. 1003-1025. http://dx.doi.org/10.1007/s10236-017-1071-2

43. Ünlüata, T., Oğuz, T., Latif, M.A. and Özsoy, E., 1990. On the Physical Oceanography of the Turkish Straits. In: L. J. Pratt, Ed., 1990. The Physical Oceanography of Sea Straits. Dordrecht: Springer, pp. 25-60. doi:10.1007/978-94-009-0677-8

44. Stanev, E.V., Pein, J., Grashorn, S., Zhang, Y. and Schrum, C., 2018. Dynamics of the Baltic Sea Straits via Numerical Simulation of Exchange Flows. Ocean Modelling, 131, pp. 40-58. doi:10.1016/j.ocemod.2018.08.009

45. Zhang, Y. and Baptista, A.M., 2008. SELFE: A Semi-Implicit Eulerian-Lagrangian Finite Element Model for Cross-Scale Ocean Circulation. Ocean Modelling, 21(3-4), pp. 71-96. https://doi.org/10.1016/j.ocemod.2007.11.005

46. Zhang, Y.J., Ateljevich, E., Yu, H.-C., Wu, C.H. and Yu, J.C.S., 2015. A New Vertical Coordinate System for a 3D Unstructured-Grid Model. Ocean Modelling, 85, pp. 16-31. http://dx.doi.org/10.1016/j.ocemod.2014.10.003

47. Codiga, D.L., 2011. Unified Tidal Analysis and Prediction Using the UTide Matlab Functions. Technical Report 2011-01. Narragansett, RI.: Graduate School of Oceanography, University of Rhode Island, 59 p. doi:10.13140/RG.2.1.3761.2008

48. Meyerjürgens, J., Ricker, M., Schakau, V., Badewien, T.H. and Stanev, E.V., 2020. Relative Dispersion of Surface Drifters in the North Sea: The Effect of Tides on Mesoscale Diffusivity. Journal of Geophysical Research: Oceans, 125(8), e2019JC015925. https://doi.org/10.1029/2019JC015925

49. Van Sebille, E., Griffies, S.M., Abernathey, R., Adams, T.P., Berloff, P., Biastoch, A., Blanke, B., Chassignet, E.P., Cheng, Y. [et al.], 2018. Ocean Modelling, 121, pp. 49-75. https://doi. org/10.1016/j.ocemod.2017.11.008

50. Hua, B.L. and Haidvogel, D.B., 1986. Numerical Simulations of the Vertical Structure of Quasi-Geostrophic Turbulence. Journal of the Atmospheric Sciences, 43(23), pp. 2923-2936. https://doi.org/10.1175/1520-0469(1986)043<2923:NSOTVS>2.0.CO;2

51. Le Traon, P.Y., Klein, P., Hua, B.L. and Dibarboure, G., 2008. Do Altimeter Wavenumber Spectra Agree with the Interior or Surface Quasigeostrophic Theory? Journal of Physical Oceanography, 38(5), pp. 1137-1142. https://doi.org/10.1175/2007JPO3806.1

52. Xu, Y. and Fu, L.-L., 2012. The Effects of Altimeter Instrument Noise on the Estimation of the Wavenumber Spectrum of Sea Surface Height. Journal of Physical Oceanography, 42(12), pp. 2229-2233. https://doi.org/10.1175/JPOD-12-0106.1

53. Dufau, C., Orsztynowicz, M., Dibarboure, G., Morrow, R. and Le Traon, P.-Y., 2016. Mesoscale Resolution Capability of Altimetry: Present and Future. Journal of Geophysical Research: Oceans, 121(7), pp. 4910-4927. https://doi.org/10.1002/2015JC010904

54. Ray, R.D. and Zaron, E.D., 2016. $\mathrm{M}_{2}$ Internal Tides and Their Observed Wavenumber Spectra from Satellite Altimetry. Journal of Physical Oceanography, 46(1), pp. 3-22. https://doi.org/10.1175/JPO-D-15-0065.1 
55. Jarosz, E., Teague, W.J., Book, J.W. and Beşiktepe, Ş., 2011. On Flow Variability in the Bosporus Strait. Journal of Geophysical Research: Oceans, 116(C8), C08038. https://doi.org/10.1029/2010JC006861

56. Simpson, J.H., Brown, J., Matthews, J. and Allen, G., 1990. Tidal Straining, Density Currents, and Stirring in the Control of Estuarine Stratification. Estuaries, 13(2), pp. 125-132. doi:10.2307/1351581

57. Nidzieko, N.J., Hench, J.L. and Monismith, S.G., 2009. Lateral Circulation in Well-Mixed and Stratified Estuarine Flows with Curvature. Journal of Physical Oceanography, 39(4), pp. 831-851. doi:10.1175/2008JPO4017.1

58. Li, M., Cheng, P., Chant, R., Valle-Levinson, A. and Arnott, K., 2014. Analysis of Vortex Dynamics of Lateral Circulation in a Straight Tidal Estuary. Journal of Physical Oceanography, 44(10), pp. 2779-2795. https://doi.org/10.1175/JPO-D-13-0212.1

About the authors:

Emil V. Stanev, Professor, Doctor, Centre for Material and Coastal Research, HelmholtzZentrum Geesthacht (Geesthacht, Germany), https://orcid.org/0000-0002-1110-8645

Marcel Ricker, Research Associate, Centre for Material and Coastal Research, HelmholtzZentrum Geesthacht (Geesthacht, Germany); Institute for Chemistry and Biology of the Marine Environment, University of Oldenburg (Oldenburg, Germany), https:// orcid.org/0000-0001-6046-6388

Sebastian Grayek, Doctor, Research Associate, Centre for Material and Coastal Research, Helmholtz-Zentrum Geesthacht (Geesthacht, Germany), https://orcid.org/0000-0002-2461-757X

Benjamin Jacob, Doctor, Research Associate, Centre for Material and Coastal Research, Helmholtz-Zentrum Geesthacht (Geesthacht, Germany), https://orcid.org/0000-0002-0045-4964

Verena Haid, Doctor, Research Associate, Centre for Material and Coastal Research, Helmholtz-Zentrum Geesthacht (Geesthacht, Germany); Alfred Wegener Institute Helmholtz Centre for Polar and Marine Research (Bremerhaven, Germany), https://orcid.org/0000-0002-9899-1740

Joanna Staneva, Doctor, Senior Research Associate, Head of Department, Centre for Material and Coastal Research, Helmholtz-Zentrum Geesthacht (Geesthacht, Germany), https://orcid.org/0000-0003-4553-392X

Contribution of the co-authors:

Emil Stanev - conceptualization, writing the manuscript

Marcel Ricker - numerical simulations and data analysis

Sebastian Grayek - development of GCOAST model and data analysis

Benjamin Jacob - analysis of numerical simulations and visualization

Verena Haid - visualisations and work on the text

Joanna Staneva - project management

All the authors have read and approved the final manuscript.

The authors declare that they have no conflict of interest. 